Document downloaded from:

http://hdl.handle.net/10251/161042

This paper must be cited as:

Caselles, A.; Soler Fernández, D.; Sanz, MT.; Micó, JC. (2020). A Methodology for Modeling and Optimizing Social Systems. Cybernetics \& Systems. 51(3):265-314.

https://doi.org/10.1080/01969722.2019.1684042

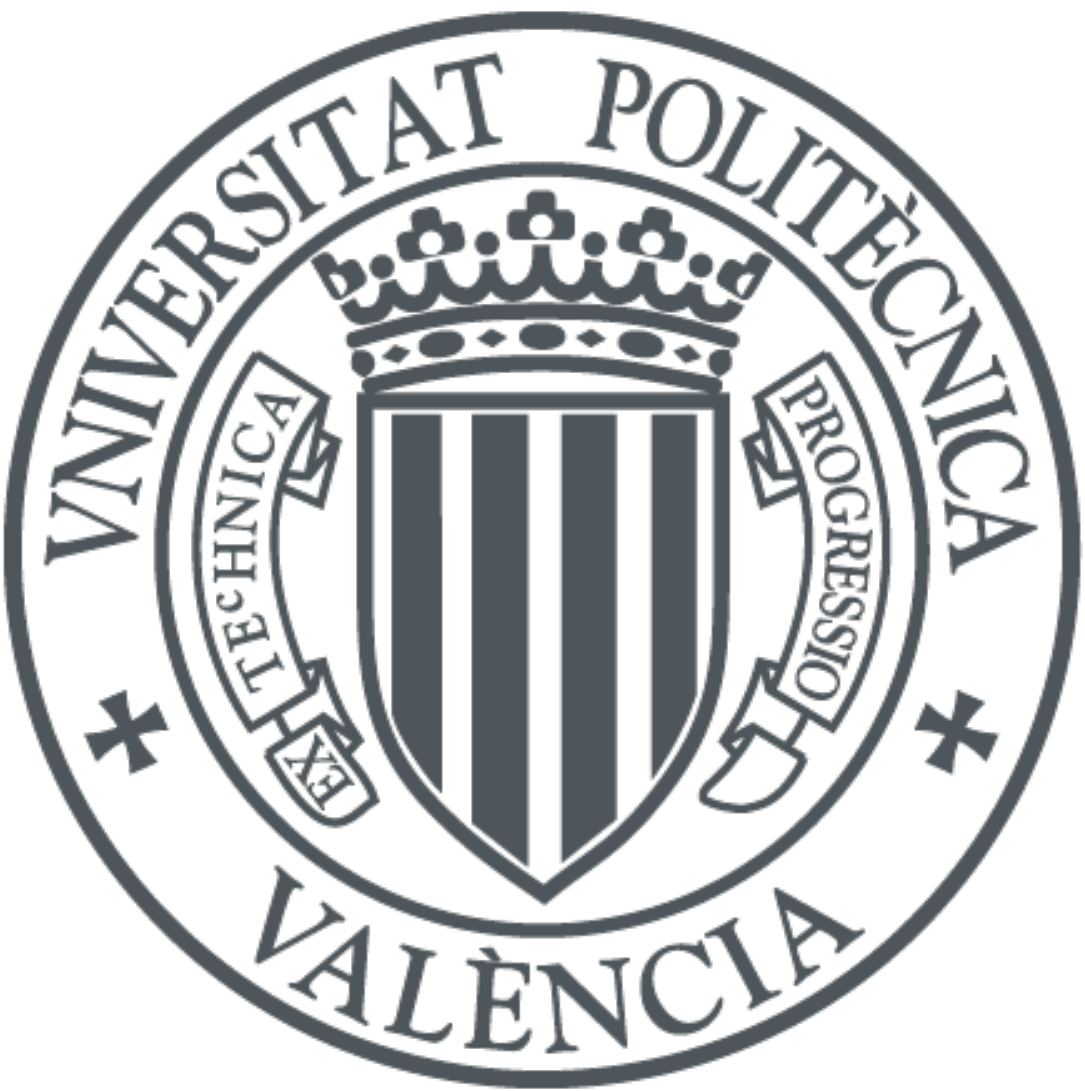

The final publication is available at

https://doi.org/10.1080/01969722.2019.1684042

Copyright Taylor \& Francis

Additional Information 


\title{
A methodology for modeling and optimizing social systems
}

Antonio Caselles. Universidad de Valencia, Departamento de Matemática Aplicada. antonio.caselles@uv.es

David Soler. Universitat Politècnica de València, Institut de Matemàtica Multidisciplinar. dsoler@mat.upv.es

Maria T. Sanz. Universidad de Valencia, Departamento de Didáctica de las Matemáticas. m.teresa.sanz@uv.es

Joan C. Micó. Universitat Politècnica de València, Institut de Matemàtica Multidisciplinar.jmico@mat.upv.es

\begin{abstract}
:
A system methodology to modeling and optimizing social systems is presented. It allows constructing dynamical models formulated stochastically, i.e., their results are given by confidence intervals. The models provide optimal intervention ways to reach the stated objectives. Two optimization methods are used: (1) testing strategies and scenarios and (2) optimizing with a genetic algorithm. The application case presented is a small nonformal education Spanish business. First, the model is validated in the 2008-2012 period, and subsequently, the optimal way to obtain a maximum profit in the 2013-2025 period is obtained using the two methods.
\end{abstract}

Keywords: Social systems; simulation; sensitivity analysis; stochastic model; genetic algorithm; strategies and scenarios; economical model. 


\section{Introduction}

In the world in which we live, wrapped with a global crisis, we must give hopes to new generations. A new general methodology is the way to solve this. The methodology will allow to model and optimize a social system, and optimal goals can be obtained to solve a specific case. The General Systems Theory provides the tool to create this, because it proposes the use of transdisciplinary methodologies that allow to build mathematical models which solve problems in the field of complex systems.

Forrester (1961) developed in the 50s the System Dynamics at the Massachusetts Institute of Technology (MIT) as transdisciplinary methodology with which to build dynamic models of complex systems and use them as a tool for intervention in them.

A continuation of the Forrester's methodology is proposed by Caselles (1994, 2008), the Methodology of General Modeling (MMG), which is used in this work, it can be implemented using intelligent generator models of complex systems SIGEM ( Caselles, 1992, 1993, 1994, 2008). Caselles et al. (1998) present an application to a complex real case (control unemployment in a country). But with this same methodology have already been solved problems such as the environment in Spain (Sanz et al., 2016), to get a demographical stable society in Austria (Sanz et al. 2013) or Spain (Sanz et al., 2014 ) or increase the life expectancy in Spain (Caselles et al., 2014).

As an example of this methodology, in this paper is presented an economic-mathematical model to optimize a small non-Spanish-formal education business.

The main advantage of the methodology presented in this paper is that it is a generic methodology applicable to any social system, holding the notion of Gutierrez et al. (2012). Shannon et al. (1976) support the use of a model-simulation methodology; they 
say: "Simulation is the process of designing a model for a real system and carry experiences with him, in order to understand the system behavior and evaluate new strategies within the limits imposed by a determined set of criteria to operate the system". In addition, the present methodology produces dynamical models and permits their stochastic formulation (Caselles, 1992, 2008). The stochastic formulation allows determining the reliability of the results for each calculation instant in two equivalent ways: (1) by presenting them with confidence intervals (for a given confidence level); (2) by their respective average values and their corresponding standard deviations.

The rest of the article is divided as follows:

- Section 2: Used methodology.

- Section 3: Presentation and explanation of the application case: the mathematical/economic model, its input and output variables and equations which related these variables.

- Section 4: Results. It is divided in two subsections: (1) the validation of the model obtained for a small business in the 2008-2012 period; (2) Those results related with simulations of the model, i.e., the sensitivity analysis, the design of future scenarios and strategies, and the genetic algorithm to determine the best actions on the input variables to maximize the objective variable.

- Section 5: Conclusions and suggestions for the future.

\section{METHODOLOGY}

The methodology suggested to design the model is the General Modeling Methodology (GMM) proposed by Caselles $(1994,2008)$ which is a widening of the methodology proposed by Forrester (1961). 
The GMM is a hypothetical-deductive methodology to build complex system models. It includes some steps and its corresponding methods to obtain the objective. These steps belong to a life-circle when if a bug is detected you have to return to the previous step to correct it and follow with the process.

These steps can be synthesized as:

- Description of the real problem.

- Conceptual model (list of variables and functional relationships among them).

- Verification and Validation.

- Simulation or optimization.

- Decision making.

Some helping tools such as the automatic programming tool SIGEM (intelligent generator of models of complex systems) and the best-function finder REGINT, are free available in http://www.uv.es/ caselles/. In this webpage more information about them can be found.

\section{APPLICATION CASE}

In the beginning, the methodology is detailed for the application case.

\subsection{Description of the real problem}

The objective consists in optimizing the benefits of a small/medium Spanish company dedicated to the non-formal education in the 2013-2025 period. Some variables are specific of this activity but the essential structure of the model can be extrapolated to any small/medium.

\subsection{Conceptual model}

The first part of this section explains how the variables of the model are identified and in the second part how the relationships among them are obtained. 


\subsubsection{Model Variables}

The method to identify model variables in this case is the "Brainstorming" (see for instance Caselles, 2008). All variables have been codified with a name of four letters. Therefore, in the variable list appears three items: the code, its meaning and its unit of measurement (bracketed) as follow,

\section{XXXX Variable explanation [unit of measurement]}

In this case, the selected variables are classified into five groups (not required by the methodology but useful for presentation), Heritage, Income, Expense, Profit and Tax Agency. Note that inside these groups the variables are alphabetically ordered (only useful for presentation). You can find more details in Appendix I.

The influence relation between the model variables is shown in the Forrester Diagram (Forrester, 1961) (Figure 1, Appendix I). In addition, the five groups of variables are differenced by color in this diagram, (Heritage: black; Income: red; Expense: orange, Profit: blue, Tax Agency: green). This is the characteristic diagram of System Dynamics, and is a hydrodynamic simile (it resembles a network of tanks connected by pipes with flows regulated by valves) that facilitates writing equations when programming a model for a computer. In this diagram the variables are classified into the following types:

- Level variables: require an initial value, which is an input variable, whose values are updated constantly. They are represented by a square or rectangle, and its meaning can be compared with a tank in which a fluid is stored.

- Flow variables: they compare with valves that regulate the flow to or from a fluid reservoir. These are represented by a characteristic icon:

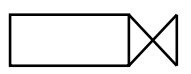

- Auxiliary variables: they are intermediate variables used to calculate flows, or are strictly output variables (which are not used in further calculations, and usually are optimizing variables). They are represented by a circle or an ellipse. 
- Control variables: input variables whose value can be assigned by the person using the model or decision maker.

- Exogenous or "scenario" variables: input variables that are non controllable.

- Constants: system parameters with a known and fixed value.

All input variables and constants are represented by a double line ellipse or circle. Sources or sinks are represented by a cloud.

\subsubsection{Functional relations}

Once all variables which are involved in the model are defined, we study the relationships (functions) among them to present them as equations or/and logical rules. Appendix II shows the equations.

\subsection{Verification and Validation}

Synthetically, verification consists in testing for errors and validation consists in testing for suitability. Good reproduction of the past values after fitting the model to the same past data is verification of the model. Good reproduction of past data after fitting the model with different past data is the commonly used and called "ex post" validation (which is not the only validation method). In the present case the method used for validation is "revision by experts".

\subsubsection{Fitting input variables}

As a step to verify the model with its stochastic formulation, all input variables are fitted respect to time. The fit has been obtained by a process of trial and error with two software tools: Mathematica 9.0 (Wolfram Mathematica, http://www.wolfram.com/) and Regint (Caselles, 1998, 2008). The last one allows us to obtain the best fitting function and provides the necessary information to write the input variables with the specific format (stochastic formulation) that Caselles $(1992,2008)$ suggests. 
The first part consists in calculating the mean value (represented by $h$ in Appendix V) using the corresponding fitted function. The second part consists in calculating the corresponding standard deviation (represented by $s$ in Appendix II). A generic variable like $Y$ is obtained as so: $Y=h+s \cdot \varepsilon(t)$., where $\varepsilon(t)$ is $N(0,1), h$ takes the following structure: $h=a+b_{1} T_{1}+b_{2} T_{2}+\ldots+b_{m} T_{m}$, and $a, b_{1}, \ldots, b_{m}$ are parameters, $T_{1}, \ldots, T_{m}$ are the functions transformed from the independent variables, and $s$ is calculated according to the following formula:

$$
s=s_{y x} \sqrt{1+\frac{1}{n}+\tau^{\prime} C \tau}
$$

Here $s_{y x}$ is the regression standard deviation, $n$ is the number of available data, the components of vector $\tau$ are the differences between the $T_{i}$ functions of the independent variables and their respective means, and $C$ is the inverse of the variances-covariances numerators matrix that corresponds to the transformed functions. For instance, Table 1 in Appendix II shows the following equation:

$$
\operatorname{TQSW}(t)=-1.42632+\frac{52}{1+0.474899 \mathrm{e}^{-1.02205(-2008+\mathrm{t})}} \quad \text { term } 1
$$

In this case, the transformed functions are only one:

$$
T_{1}=\frac{1}{1+0.474899 \mathrm{e}^{-1.02205(-2008+\mathrm{t})}}
$$

Matrix $\mathrm{C}$ is:

$$
(0.0055061)
$$

The mean of the transformed function is:

$$
\mathrm{T}_{1}=46.223568
$$

The standard deviation is:

$$
s=1.573375
$$

This information has been used in the model as follow, $\mathrm{h}=-1.42632+52 /(1+0.474899 * \operatorname{Exp}(-1.02205 *(-2008+$ tems $)))$ 
$\mathrm{A}=1 /(1+0.474899 * \operatorname{Exp}(-1.02205 *(-2008+$ tems $)))-46.223568$

$\mathrm{s}=1.57337{ }^{*} \operatorname{sqr}(1+1 / 48+0.0055061 * \mathrm{~A} * \mathrm{~A})$

Historical data have been obtained from the quarterly results for the 2008-2012 period of the business used as an example.

To verify the fitted functions, we calculate the coefficient of determination $\left(\mathrm{R}^{2}\right)$. The residuals have been tested for normality (using the Kolmogorov-Smirnov test).

Appendix III presents these results for all input variables.

\subsubsection{Model Verification}

\section{Verification using the model's deterministic formulation}

The model has been written as a set of finite difference equations and the solutions have been computed with Euler approximation, following Djidjeli et al (1998), where they explain that Euler's method is most appropriate to solve these equations in similar situations.

Verification is graphically displayed and the results for each quarter and the corresponding historical data have been superimposed. Also, the model has been verified numerically in two ways: calculating the coefficients of determination and testing the randomness of the residuals (Figures 43 and 44).

(Please insert Figure 43 about here)

(Please insert Figure 44 about here)

The result is satisfactory because:

- The graphic overlay is very good.

- The coefficient of determination (calculated with equation [2]) is very high $\left(\mathrm{R}^{2}=\right.$ $0.996831)$

$$
\mathrm{R}^{2}=\frac{\left(\sum_{\mathrm{i}}\left(\mathrm{x}_{\mathrm{i}}-\mu_{\mathrm{x}}\right)\left(\mathrm{y}_{\mathrm{i}}-\mu_{\mathrm{y}}\right)\right)^{2}}{\sum_{\mathrm{i}}\left(\mathrm{x}_{\mathrm{i}}-\mu_{\mathrm{x}}\right)^{2} \sum_{\mathrm{i}}\left(\mathrm{y}_{\mathrm{i}}-\mu_{\mathrm{y}}\right)^{2},}
$$


where $\left(x_{i}, y_{i}\right)$ are data and $\mu_{x} \mathrm{y} \mu_{y}$ are the respective averages.

- In addition, the maximum relative error is lower than $5 \%$.

Figure 43 shows that the maximum income corresponds to the third quarter of each year. During July, August and September, a greater influx of students occurs in order to prepare the September exam.

\section{Verification using the model's stochastic formulation}

The stochastic formulation of the model allows us to determine the reliability of the results (each result is obtained with its respective confidence interval or with its own mean and standard deviation).

The central equations of the stochastic formulation of the model of this business are the same as in its deterministic model. The difference between both models is in the input variables, which in this case are written as stochastic functions of time (explained in 3.3.1).

The procedure to verify that the stochastic formulation of the model is correct is the following:

- Noting that all results are normally distributed (for this purpose, SIGEM programs automatically a $\chi 2$ test).

- Calculating a confidence interval of $95 \%$ (for instance) for each outcome and checking that all historical data is within this range.

The data corresponding to the stochastic formulation verification are presented in Figure 44 , confirming that the model is valid for the small business case that has served as an example.

(Please insert Figure 43 about here)

(Please insert Figure 44 about here) 


\subsection{Simulation and Decision Making}

The methodology presented in this article allows using two different ways to optimize the results of these models. On the one hand the design and test of strategies and scenarios is set up and, on the other hand, the optimization in each by means of a genetic algorithm is put in practice. Both processes are explained with detail in the following, taking into account that the objective-variable to optimize must be defined.

In the study case the objective-variable is the benefits to end of year, trying to maximize it in the 2013-2025 period.

\subsubsection{Strategies and scenarios}

A previous step to design and to test strategies and scenarios is discovering what variables have more influence on the objective-variable. In order to determine them a sensitivity analysis is made. Sensitivity Analysis is here considered as the study of the impact that a small change in an input variable has on an output variable considering the model as of black-box type. But obviously, this output variable could be also affected by the rest of input variables. Therefore, to see the real effect of each input variable on the given output variable, the other input variables must be considered as constants or a random sample of all their possible combined values must be taken. In other cases the analysis would be only valid for the considered concrete situation. An instance of this approach can be found in a book of Caselles et al. (1999).

Some methodological remarks:

- The input variables are assumed to be independent.

- The values of the input variables are recomputed as the following relative values:

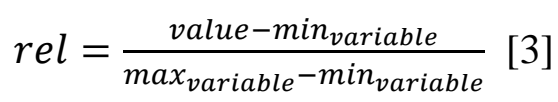

- The $R^{2}$ coefficient determines the fraction of the variability of the output variable that is explained by the function of the corresponding input variables. 
- If the data corresponding to input variables do not come from a random sample, the conclusions are only valid for the considered situation. In this paper a random sample is considered, because the simulator generated by SIGEM is able to do this.

- The data are fitted by linear or quadratic functions: $y=m x+n$, where $m$ gives the increasing or decreasing rate, or $y=a x^{2}+b x+c$, where the increasing or decreasing rate is determined by the derivative function $2 a x+b$.

In our example, determining what input variables are the most influencing on the objective variable $P A T Q$ (the quarterly year after tax) has been tried. In Appendix IV these influences are shown (Table 41 and 42). Table 41 shows the relations between $P A T Q$ and the model input variables in the $2008-2012$ period. Table 42 is equivalent to Table 41 but with the simulated data for the 2013-2025 period.

The determination coefficient indicates the proportion of the observed variability that is explained by the function that has been fitted.

According to Table 42, the most relevant input variables are expenses in water $(T Q S W)$, light (TQSL) and others (OQEX), as well as the number of students of type 1 (QST1) and the number of students of type 4 (QST4). To interpret these relationships, for example, in the case of the first variable, $T Q S W$, an increase of one euro in a quarter year in the 20132025 period, $T Q S W$, corresponds with an increase of 20.32 Euros in $P A T Q$. We want to emphasize that this relationship is not a causal relation but a correlation.

Regarding the variables involved in incomes, we have that type 1 students, QST1, (students who attend the center 3 hours weekly) and type 4 students, QST4, (tutorials) are the most relevant. Note (Table 42) that the increase of one person in tutorials (QST4) in the 2013-2025 period is associated with a decrease of approximately 157 Euros in PATQ. This fact has an obvious explanation: benefit is greater with group classes (group classes have usually 5-6 people, equivalent to about $40 € / \mathrm{h}$, while tutorials are about $15 € / \mathrm{h}$ ). 
We have observed with the sensitivity analysis what variables are most correlated with the main variable. In the beginning, we are going to make simulated predictions with the model. To do this, we extrapolate all input variables. EXTRAPOL is the tool that allows extrapolating the trend of the input variables with its confidence interval from a function previously obtained with REGINT. This tool can be found free in http://www.uv.es/ caselles/.

From this point, input variables must be classified into control variables (those controllable by decision makers) and scenario variables (those non controllable).

On the one hand, as the sensitivity analysis reveals, the variables most correlated with the objective variable are TQSW, TQSL and $O Q E X$, which will be assumed as scenario variables due to the difficulty to its control. Note that the use of light, water and others can be controlled but not its price.

On the other hand, the variables related with the number of students, specifically those of type 1 and type 4, QST4 and QST1, are assumed as control variables, because the business may carry out mechanisms that empower one or the other.

The considered tentative strategies and scenarios are:

- Strategy 1: strengthen the number of students of type 1, QST1, increase its trend and restrict the number of students of type 4, QST4. To do this, the extrapolated values of QST1 will be increased by $2 \%$ (provisional value) and in QST4 their values will be decreased by $1 \%$.

- Strategy 2: strengthen the number of students of type 1, QST1, above their trend and keep the trend of the number of students of type 4, QST4. To do this, the extrapolated values of QST1 will be increased by $2 \%$ (provisional value) and in QST4 their extrapolated values will keep its trend. 
- Strategy 3: keep the trend of the number of students of type 1, QST1, and restrict the number of students of type 4 QST4. For this case, the values of QST1 keep their trend and those of QST4 decrease $1 \%$.

- Strategy 4: keep the trend of the number of students of type 1, QST1, and that of the number of students of type 4, QST4. For this case, both, QST1 and QST4 will take the values of their extrapolated trend.

- Scenario 1, trend: to keep the trend in variables related with expenses.

- Scenario 2, pessimistic: to increase expenses by $2 \%$ above its trend.

- Scenario 3, optimistic: to reduce expenses by $2 \%$ below its trend.

The hypothetical probability assigned to each scenario is:

- Scenario 1: $p_{1}=0.3$

- Scenario 2: $p_{2}=0.2$

- Scenario 3: $p_{3}=0.5$

In this case, the objective of the business is to maximize the cumulative quarterly results after applying the tax of the 2013-2025 period. To accumulate the values of $P A T Q$, we define $A C U M_{\mathrm{ij}}$, where index $i$ represents a possible strategy and index $j$ represents a possible scenario. The variable that characterizes each strategy is $z o p t_{i}$ calculated as follows:

$$
\text { zopt } 1_{i}=\sum_{j} A C U M_{i j} * p_{j}
$$

where $p_{j}$ is the probability that experts assign to scenario $j$. The maximum value of this variable indicates which strategy should be selected. 
The corresponding calculations are performed with the simulator generated by SIGEM. The optimal strategy to achieve the goal is chosen watching the results of $z$ opt $1, i=1, \ldots, 4$ :

$$
\begin{aligned}
& \text { zopt1 }_{1}: € 105834 \\
& \text { zopt }_{2}: € 105499 \\
& \text { zopt }_{3}: € 102841 \\
& \text { zopt }_{4}: € 102700
\end{aligned}
$$

According to these results, Strategy 1 produces a greater profit in the 2013-2025 period. In Figure 45 the annual evolution of $P A T Q$ can be observed as well as that the greatest benefit after tax in 2025 corresponds to the Strategy 1, noticing, as expected, higher increase in scenario 3 than in the other scenarios.

(Please insert Figure 45 about here)

After determining the optimal strategy for maximum benefit of the business, let see in this specific optimal situation, what will be the Active, Equity and Passive during the study period.

Note that the existing active at the start of the activity (2008) amounted to $€ 175,000$ and passive of that year was worth $€ 150,000$. With these two values the equity of the business was $€ 25,000$.

In Tables 43, 44 and Figure 46 the Active, Passive and Equity at the beginning of each year are shown. The maximum and minimum values are presented, between these values the true value can be found with $95 \%$ confidence.

(Please insert Tables 43, 44 and 46 about here) 


\subsubsection{Optimization with a Genetic Algorithm}

A genetic algorithm can be automatically programmed by SIGEM inside the simulator. The genetic algorithm (GA) allows optimizing, in each time step, an objective variable previously defined from other variables included in the model (it is one of them). This variable is named OBJE, and is the one that the program tries to minimize. In the application case the objective is to maximize PATQ, for that reason the equation that calculates OBJE will be:

$$
O B J E=-P A T Q
$$

The difference between the optimization obtained with the GA and the quasi-optimization obtained with the method of strategies and scenarios displayed in 3.4.1 consists in that the input variables which were fitted to time and its trend evolution were tentatively increased or decreased to design feasible strategies (the control variables), now are calculated by the model by means of the GA. The GA looks for the optimal strategy to reach the objective. The GA needs that the names of these control variables are introduced in a vector named as CROM (chromosome). This variable has an initial-value-variable, CROI, in which the initial values of the variables inside the chromosome corresponding to the period that is desired to simulate are placed. In the present case CROI contains the data of the last fourth month period of the year 2012, that is, the feasible starting point. Also another new variable is needed, PCRO, in which the user will mark the minimum and maximum values between which the variables located in CROM will be able to take value (in opinion of experts). The values that have been assigned to variables CROM, CROI and PCRO can be seen in Table 45.

\section{(Please insert Tables 45 about here)}

Once the simulator is generated by SIGEM and at the beginning to use it, the following data are asked to the user: $\mathrm{N}^{\circ}$ of individuals of the population $(\mathrm{N}) ; \%$ of reproducers $(\mathrm{R})$; 
$\mathrm{N}^{\mathrm{o}}$ of immigrants in each generation (I); Rate of mutants (per thousand) (M); $\mathrm{N}^{\mathrm{o}}$ of generations $(\mathrm{G})$; $\mathrm{N}^{\mathrm{o}}$ of iterations of the genetic algorithm (updates of the initial values). (IT).

\section{How the GA works?}

The GA obtains random values (within the rank marked in PCRO) for each one of the CROM variables, obtaining therefore an individual of the population, and proceeding of this manner until completing the size of the population $(\mathrm{N})$. Variable OBJE is calculated for each one of the individuals of the population. They are ordered of minor to greater value (notice than the program minimizes OBJE). The first $\mathrm{R}$ ones are kept and the rest is eliminated. Once finalized this process, immigrants (I) are defined (randomly) and are written after the $\mathrm{R}$ ones. The resting population is created by random cross-over within the $\mathrm{R}+\mathrm{I}$ ones considering $\mathrm{M}$. The cycle is repeated until completing $\mathrm{N}$. The new values that now CROM has are taken like initial values to make the following iteration of the GA until completing IT. Observe that this procedure is designed to guarantee not to fall into local minima and to be as simple (and quick) as possible.

The results obtained in the application case have been the following ones

\section{(Please insert Tables 46 to 49 about here)}

In Tables 46, 47, 48 and 49 the Profit, Active, Passive and Equity at the beginning of each year are shown. The maximum and minimum values of each variable are presented. Between these values the true value can be found with $95 \%$ confidence. We can see that its tendency is the same than the observed one with the scenarios and strategies method. We also show the values of the control variables that must be used to reach the optimal ones. Note that QST1 and QST4 follow the same tendency that was determined by the strategies and scenarios method, that is to say, to increase the first and to diminish the second. This fact makes the results of both methods consistent. 


\section{CONCLUSIONS}

A methodology to construct dynamic mathematical models to model and optimize some social system has been presented. The application case has been validated for a study center, where non-formal education is imparted, in 2008-2012 period. The variables used in the model are taken from the Spanish General Accounting Plan for Small and Medium Enterprises (Official State Bulletin (BOE), num. 279). It is a general methodology, i.e., it can be used by any other business, saving the differences of the special activity.

All the variables and relationships between them are described. The model has been written in its deterministic and stochastic formulations, and a positive validation has been obtained for both formulations. We have used the results of the quarterly financial year after tax as a variable to validate the model. In the deterministic formulation the determination coefficient is higher than 0.99 and a relative error do not exceed $5 \%$. Similar is the situation in the stochastic formulation, where real data are between maximum and minimum values of the $95 \%$ simulated confidence interval.

Simulation of the future has been made by means of two different methods: testing strategies and scenarios and optimizing by means of a genetic algorithm.

In the strategies and scenarios method a sensitivity analysis has been performed to observe which input variables are more closely correlated with the objective variable (result for the quarterly year after tax). Costs of water, electricity and other expenses, as well as the number of students of types 1 and 4 are variables with greater correlation with profit. These most correlated variables with the goal variable have been used to propose different possible strategies and scenarios. Concretely, four strategies and three scenarios have been proposed to determine which strategy would maximize the cumulative result 
of the quarterly financial year after tax for the $2013-2025$ period. It is concluded that an increase of $2 \%$ (provisional value) on the trend in the number of students in Type 1 and a decrease of $1 \%$ (provisional value) of students in Type 4, and a decrease in expenses, causes the maximum benefit in this period.

All the control variables have been used to optimize with the genetic algorithm and the obtained results are equivalent to those obtained using the strategies and scenarios method. For future work we intend to apply this methodology to other economic and social problems in cities and regions.

\section{References}

Caselles, A., 1992. Simulation of Large Scale Stochastic Systems. In Cybernetics and Systems'92. R. Trappl (ed.). Singapore. World Scientific. 221-228.

Caselles, A., 1994. Improvements in the Systems Based Program Generator SIGEM. Cybernetics and Systems: An International Journal. 25, 81-103.

Caselles, A., 1998. A tool for discovery by complex function fitting. In Cybernetics and Systems Research'98. R. Trappl (ed.). Vienna. Austrian Society for Cybernetic Studies, 787-792.

Caselles, A., 2008. Modelización y simulación de sistemas complejos. Editorial: Universitat de València.

Caselles, A., Soler, D., Sanz, M.T., Mico, J.C. 2014. Simulating Demography ans Human Developments Dynamics. Cybernetics and Systems: An International Journal. 45, 465-485.

Djidjeli A, W.G. Price A, P. Temarel A, \& E.H. Twizell B., 1998. Partially implicit schemes for the numerical solutions of some non-linear differential equations. Applied Mathematics and Computation, 96, 177-207. 
Forrester, J. W., 1961. Industrial dynamics. Cambridge: MIT Press.

Garcia M., Serrano F., 1990. La Modelización del comportamiento de sistemas económicos (A través de la dinámica de sistemas y la contabilidad circulatoria). Revista Española de Financiación y contabilidad, XX, 62, 45-114.

Micó, J.C., Caselles, A., Soler, D., 2006. Age-Structured Human Population Dynamics. Journal of Mathematical Sociology, 30, 1-31.

Sanz, M.T., Micó, J.C., Caselles, A., Soler, D. 2013. Welfare Human and Population in Austria. Systems. Connecting matter, life, culture and technology, 1 (2), 60-82.

Sanz, M.T., Micó, J.C., Caselles, A., Soler, D. 2014. A Stochastic model for population and well-being dynamics. Journal of Mathematical Sociology, 38, 75-94.

Sanz, M.T., Caselles, A., Micó, J.C., Soler, D. (2016). Including an environmental quality index in a demographic model. International Journal in the Global Warming, 9(3), 362-396.

Shannon, R., Johannes, J., 1976. Systems simulation: the art and science. IEEE Transactions on Systems, Man and Cybernetics, 6(10), 7234-724.

http://www.boe.es/buscar/doc.php?id=BOE-A-2007-19966. Official State Bulletin (BOE), num.279. 


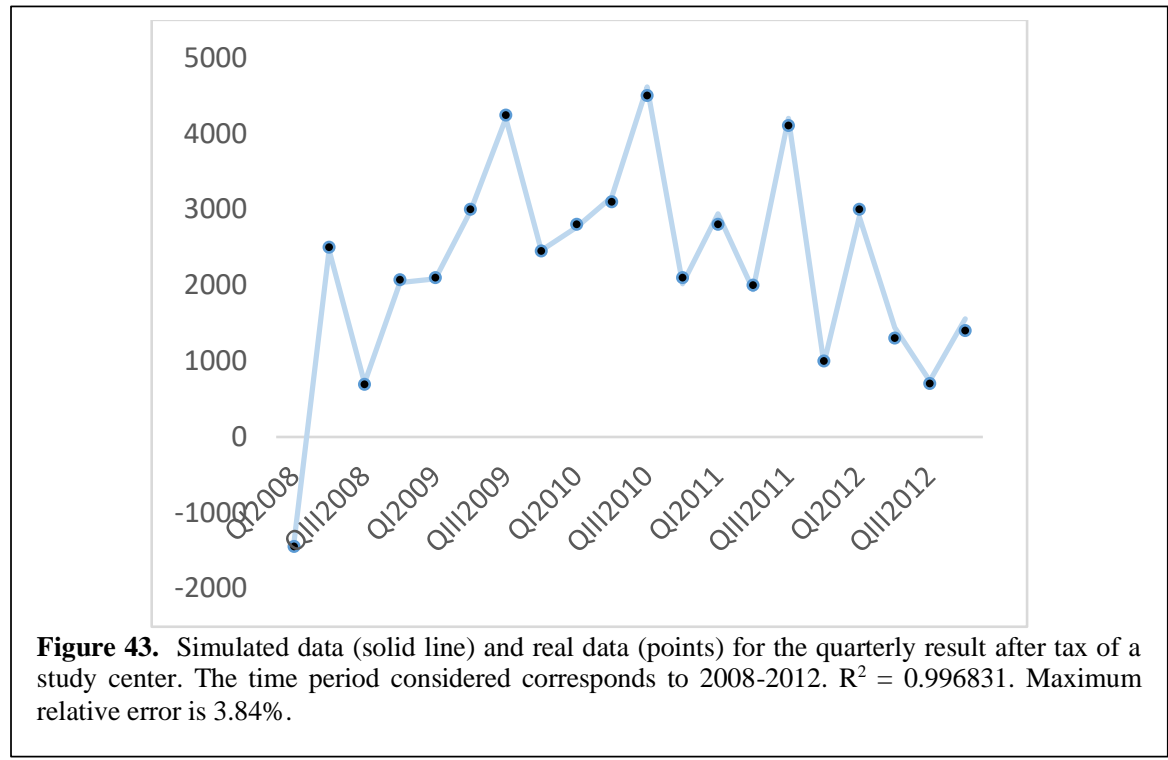




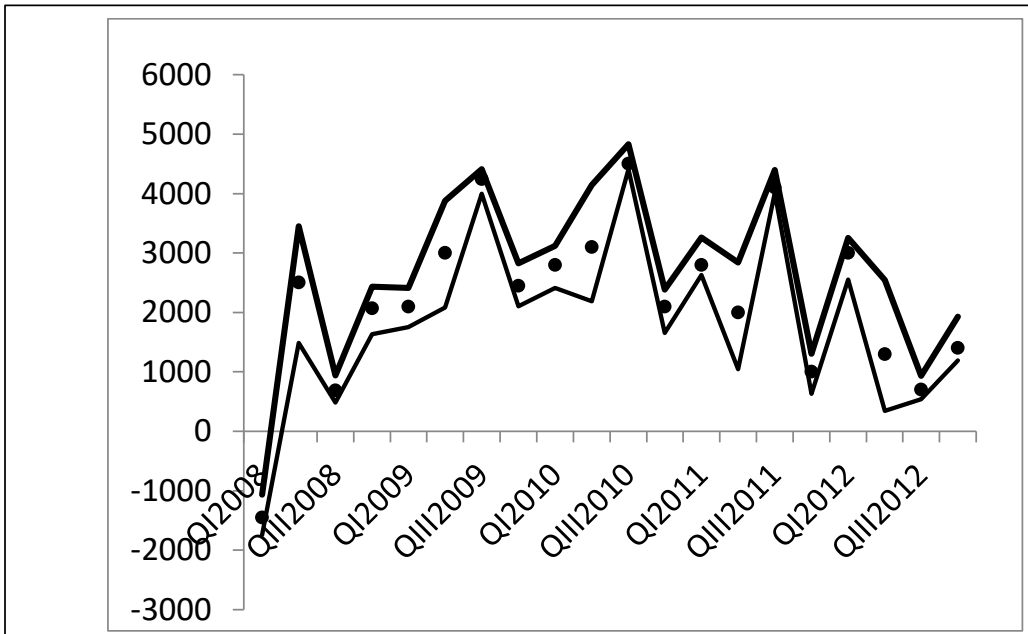

Figure 44. Simulated data, maximum and minimum (solid line) and real data (points) for the quarterly result after tax of a study center. The time period considered corresponds to 2008-2012. 


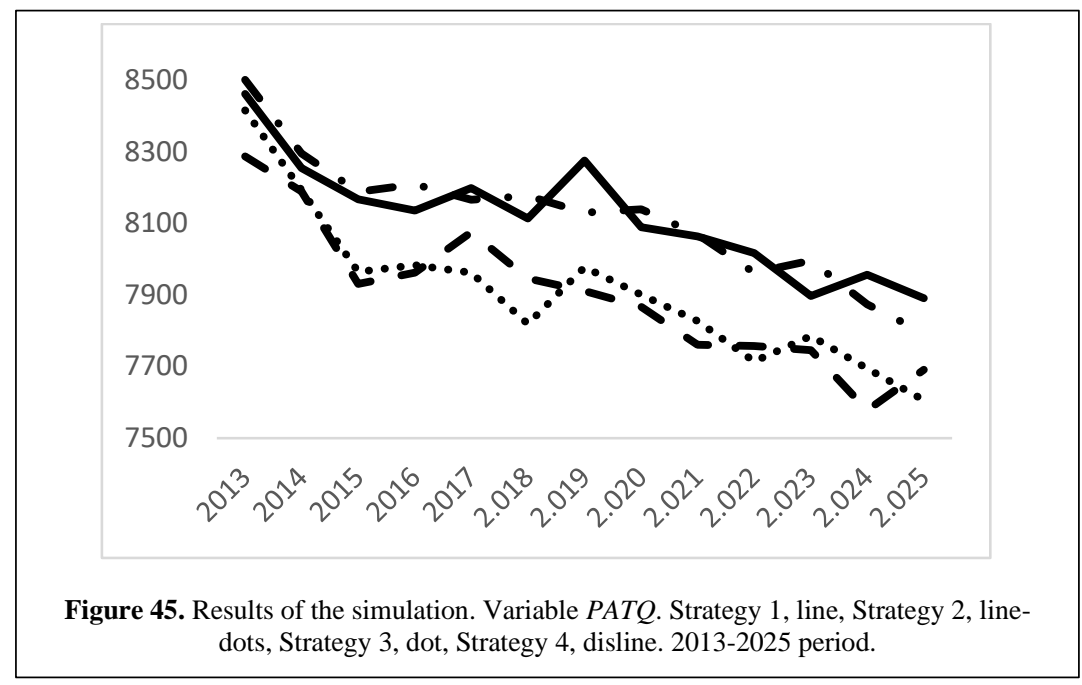




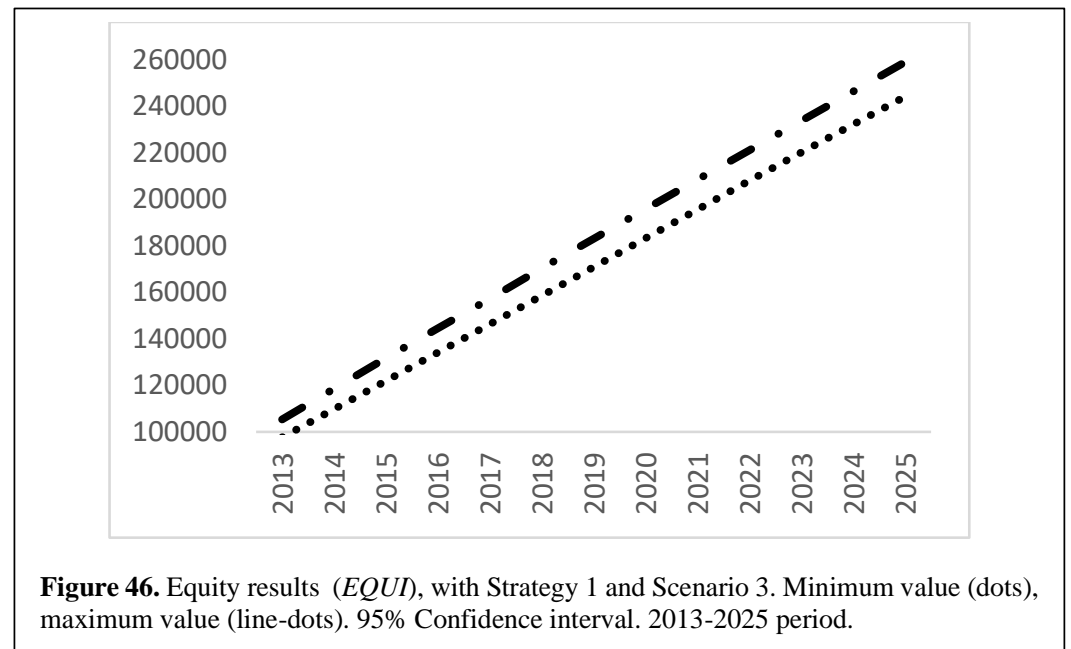




\begin{tabular}{|c|c|c|}
\hline Year & Minimum & Maximum \\
\hline $\mathbf{2 0 1 3}$ & 127657.5 & 128404.7 \\
\hline $\mathbf{2 0 1 4}$ & 123308 & 124004.2 \\
\hline $\mathbf{2 0 1 5}$ & 118964.5 & 119597.7 \\
\hline $\mathbf{2 0 1 6}$ & 114563.1 & 115249.1 \\
\hline $\mathbf{2 0 1 7}$ & 110112.6 & 110949.6 \\
\hline $\mathbf{2 0 1 8}$ & 105747.6 & 106564.6 \\
\hline $\mathbf{2 0 1 9}$ & 101522.4 & 102039.8 \\
\hline $\mathbf{2 0 2 0}$ & 97085.5 & 97726.69 \\
\hline $\mathbf{2 0 2 1}$ & 92719.81 & 93342.39 \\
\hline $\mathbf{2 0 2 2}$ & 88364.54 & 88947.66 \\
\hline $\mathbf{2 0 2 3}$ & 84052.96 & 84509.26 \\
\hline $\mathbf{2 0 2 4}$ & 79580.15 & 80232.07 \\
\hline $\mathbf{2 0 2 5}$ & 75252.86 & 75809.38 \\
\hline
\end{tabular}

Table 43. Passive results (LIAB), with Strategy 1 and Scenario 3. 95\% Confidence Interval. 2013-2025 period. 


\begin{tabular}{|c|c|c|}
\hline Year & Minimum & Maximum \\
\hline $\mathbf{2 0 1 3}$ & 225676.3 & 233385.5 \\
\hline $\mathbf{2 0 1 4}$ & 233464 & 242258.6 \\
\hline $\mathbf{2 0 1 5}$ & 241161.6 & 251045.4 \\
\hline $\mathbf{2 0 1 6}$ & 249019.5 & 259512.5 \\
\hline $\mathbf{2 0 1 7}$ & 256968.4 & 267898.2 \\
\hline $\mathbf{2 0 1 8}$ & 264776.5 & 276602.5 \\
\hline $\mathbf{2 0 1 9}$ & 272626 & 284883.3 \\
\hline $\mathbf{2 0 2 0}$ & 280783.3 & 293244.4 \\
\hline $\mathbf{2 0 2 1}$ & 288776.9 & 301584.1 \\
\hline $\mathbf{2 0 2 2}$ & 296660.1 & 309858.8 \\
\hline $\mathbf{2 0 2 3}$ & 304474 & 318140.6 \\
\hline $\mathbf{2 0 2 4}$ & 312107.6 & 326310.4 \\
\hline $\mathbf{2 0 2 5}$ & 319788.2 & 334696.2 \\
\hline
\end{tabular}

Table 44. Active results (ASST), with Strategy 1 and Scenario 3. 95\% Confidence Interval. 2013-2025 period. 


\begin{tabular}{|c|c|c|c|}
\hline CROM & CROI & \multicolumn{2}{|c|}{ PCRO } \\
\hline QST1 & 10 & 1 & 100 \\
\hline QST2 & 7 & 1 & 100 \\
\hline QST3 & 3 & 1 & 100 \\
\hline QST4 & 2 & 1 & 100 \\
\hline PBMR & 0.7 & 0.25 & 0.9 \\
\hline DRFU & 0.025 & 0.01 & 0.05 \\
\hline DRCO & 0.1 & 0.05 & 0.2 \\
\hline DRRE & 0.005 & 0.0025 & 0.0075 \\
\hline RCQU & 0.99 & 0.7 & 1 \\
\hline $\begin{array}{l}\text { Table 45. Values of the control variables for the genetic } \\
\text { algorithm: CROI (initial ones); PCRO (tentative minimum and } \\
\text { maximum ones). }\end{array}$ \\
\hline
\end{tabular}




\begin{tabular}{|r|r|r|}
\hline Year & \multicolumn{1}{|c|}{ Minimum } & \multicolumn{1}{|c|}{ Maximum } \\
\hline $\mathbf{2 0 1 3}$ & 1446.9847 & 4487.5657 \\
\hline $\mathbf{2 0 1 4}$ & 865.8411 & 3911.835 \\
\hline $\mathbf{2 0 1 5}$ & 584.4804 & 3589.00796 \\
\hline $\mathbf{2 0 1 6}$ & 452.6224 & 3398.54859 \\
\hline $\mathbf{2 0 1 7}$ & 395.5638 & 3288.1947 \\
\hline $\mathbf{2 0 1 8}$ & 399.0916 & 3207.665 \\
\hline $\mathbf{2 0 1 9}$ & 358.5355 & 3195.8564 \\
\hline $\mathbf{2 0 2 0}$ & 313.4034 & 3135.1336 \\
\hline $\mathbf{2 0 2 1}$ & 298.01885 & 3099.1768 \\
\hline $\mathbf{2 0 2 2}$ & 299.26352 & 3097.2343 \\
\hline $\mathbf{2 0 2 3}$ & 300.54109 & 3104.1628 \\
\hline $\mathbf{2 0 2 4}$ & 303.7415 & 3111.6876 \\
\hline $\mathbf{2 0 2 5}$ & 305.5456 & 3111.742 \\
\hline
\end{tabular}




\begin{tabular}{|r|r|r|}
\hline Year & Minimum & Maximum \\
\hline $\mathbf{2 0 1 3}$ & 270106.26 & 318944.52 \\
\hline $\mathbf{2 0 1 4}$ & 293904.96 & 350021.36 \\
\hline $\mathbf{2 0 1 5}$ & 315842.54 & 379819.68 \\
\hline $\mathbf{2 0 1 6}$ & 336649.57 & 409091.06 \\
\hline $\mathbf{2 0 1 7}$ & 356841.26 & 438110.9 \\
\hline $\mathbf{2 0 1 8}$ & 376839.56 & 466884.3 \\
\hline $\mathbf{2 0 1 9}$ & 396581.14 & 495719.1 \\
\hline $\mathbf{2 0 2 0}$ & 416149.6 & 524322.8 \\
\hline $\mathbf{2 0 2 1}$ & 435538.6 & 552813 \\
\hline $\mathbf{2 0 2 2}$ & 454762.8 & 581409 \\
\hline $\mathbf{2 0 2 3}$ & 473854.2 & 610157.1 \\
\hline $\mathbf{2 0 2 4}$ & 492848.1 & 639049 \\
\hline $\mathbf{2 0 2 5}$ & 511758.1 & 668046.4 \\
\hline
\end{tabular}

Table 47. Equity results (EQUI). 95\% Confidence Interval. 2013-2025 period. 


\begin{tabular}{|l|r|r|}
\hline Year & Minimum & Maximum \\
\hline $\mathbf{2 0 1 3}$ & 518642.4 & 519371.2 \\
\hline $\mathbf{2 0 1 4}$ & 501441.7 & 502218.1 \\
\hline $\mathbf{2 0 1 5}$ & 484272.7 & 485080.3 \\
\hline $\mathbf{2 0 1 6}$ & 467117.7 & 467949.5 \\
\hline $\mathbf{2 0 1 7}$ & 449975.1 & 450824.7 \\
\hline $\mathbf{2 0 1 8}$ & 432835.6 & 433703.2 \\
\hline $\mathbf{2 0 1 9}$ & 415701.8 & 416587.4 \\
\hline $\mathbf{2 0 2 0}$ & 398571.99 & 399476.9 \\
\hline $\mathbf{2 0 2 1}$ & 381449.06 & 382361.79 \\
\hline $\mathbf{2 0 2 2}$ & 364330.92 & 365244.75 \\
\hline $\mathbf{2 0 2 3}$ & 347212.78 & 348127.76 \\
\hline $\mathbf{2 0 2 4}$ & 330093.16 & 331008.82 \\
\hline $\mathbf{2 0 2 5}$ & 312973.52 & 313892.05 \\
\hline
\end{tabular}




\begin{tabular}{|r|r|r|}
\hline Year & Minimum & Maximum \\
\hline $\mathbf{2 0 1 3}$ & 789137.5 & 837926.5 \\
\hline $\mathbf{2 0 1 4}$ & 795750.1 & 851835.7 \\
\hline $\mathbf{2 0 1 5}$ & 800530 & 864485 \\
\hline $\mathbf{2 . 0 1 6}$ & 804196 & 876611 \\
\hline $\mathbf{2 . 0 1 7}$ & 807257 & 888494 \\
\hline $\mathbf{2 0 1 8}$ & 810129.8 & 900133 \\
\hline $\mathbf{2 0 1 9}$ & 812748.2 & 911841.7 \\
\hline $\mathbf{2 0 2 0}$ & 815196.5 & 923325 \\
\hline $\mathbf{2 . 0 2 1}$ & 817466 & 934697 \\
\hline $\mathbf{2 . 0 2 2}$ & 819573 & 946175 \\
\hline $\mathbf{2 0 2 3}$ & 821547.3 & 957804.5 \\
\hline $\mathbf{2 0 2 4}$ & 823422.3 & 969576.5 \\
\hline $\mathbf{2 0 2 5}$ & 825215 & 981455 \\
\hline
\end{tabular}

Table 49. Active results (ASST). 95\% Confidence Interval. 2013-2025 period. 


\begin{tabular}{|l|r|r|}
\hline Year & Minimum & Maximum \\
\hline $\mathbf{2 0 1 3}$ & 80.51 & 88.12 \\
\hline $\mathbf{2 0 1 4}$ & 84.13 & 91.68 \\
\hline $\mathbf{2 0 1 5}$ & 87.25 & 94.23 \\
\hline $\mathbf{2 0 1 6}$ & 89.52 & 96.46 \\
\hline $\mathbf{2 0 1 7}$ & 91.20 & 98.00 \\
\hline $\mathbf{2 0 1 8}$ & 93.08 & 99.15 \\
\hline $\mathbf{2 0 1 9}$ & 94.63 & 99.94 \\
\hline $\mathbf{2 0 2 0}$ & 95.58 & 100.67 \\
\hline $\mathbf{2 0 2 1}$ & 96.35 & 101.41 \\
\hline $\mathbf{2 0 2 2}$ & 96.60 & 101.99 \\
\hline $\mathbf{2 0 2 3}$ & 97.02 & 102.61 \\
\hline $\mathbf{2 0 2 4}$ & 97.57 & 103.21 \\
\hline $\mathbf{2 0 2 5}$ & 97.85 & 103.34 \\
\hline
\end{tabular}

Table 50. Quarterly students with type 1 fee results (QST1). 95\% Confidence Interval. 2013-2025 period. 


\begin{tabular}{|l|r|r|}
\hline Year & Minimum & Maximum \\
\hline $\mathbf{2 0 1 3}$ & 19.47 & 27.28 \\
\hline $\mathbf{2 0 1 4}$ & 17.27 & 24.76 \\
\hline $\mathbf{2 0 1 5}$ & 15.74 & 22.51 \\
\hline $\mathbf{2 0 1 6}$ & 14.05 & 20.89 \\
\hline $\mathbf{2 0 1 7}$ & 12.90 & 19.59 \\
\hline $\mathbf{2 0 1 8}$ & 12.04 & 17.96 \\
\hline $\mathbf{2 0 1 9}$ & 11.31 & 16.59 \\
\hline $\mathbf{2 0 2 0}$ & 10.58 & 15.72 \\
\hline $\mathbf{2 0 2 1}$ & 9.85 & 14.96 \\
\hline $\mathbf{2 0 2 2}$ & 9.26 & 14.72 \\
\hline $\mathbf{2 0 2 3}$ & 8.75 & 14.21 \\
\hline $\mathbf{2 0 2 4}$ & 8.14 & 13.70 \\
\hline $\mathbf{2 0 2 5}$ & 7.96 & 13.40 \\
\hline
\end{tabular}




\begin{tabular}{|l|r|r|}
\hline Year & Minimum & Maximum \\
\hline $\mathbf{2 0 1 3}$ & 6.59 & 9.13 \\
\hline $\mathbf{2 0 1 4}$ & 5.67 & 7.85 \\
\hline $\mathbf{2 0 1 5}$ & 4.87 & 6.82 \\
\hline $\mathbf{2 0 1 6}$ & 4.42 & 6.10 \\
\hline $\mathbf{2 0 1 7}$ & 4.16 & 5.62 \\
\hline $\mathbf{2 0 1 8}$ & 4.08 & 5.18 \\
\hline $\mathbf{2 0 1 9}$ & 4.08 & 4.93 \\
\hline $\mathbf{2 0 2 0}$ & 4.08 & 4.87 \\
\hline $\mathbf{2 0 2 1}$ & 4.08 & 4.84 \\
\hline $\mathbf{2 0 2 2}$ & 4.11 & 4.84 \\
\hline $\mathbf{2 0 2 3}$ & 4.09 & 4.82 \\
\hline $\mathbf{2 0 2 4}$ & 4.07 & 4.79 \\
\hline $\mathbf{2 0 2 5}$ & 4.11 & 4.84 \\
\hline
\end{tabular}




\begin{tabular}{|l|r|r|}
\hline Year & Minimum & Maximum \\
\hline $\mathbf{2 0 1 3}$ & 4.03 & 4.68 \\
\hline $\mathbf{2 0 1 4}$ & 4.03 & 4.40 \\
\hline $\mathbf{2 0 1 5}$ & 4.03 & 4.38 \\
\hline $\mathbf{2 0 1 6}$ & 4.03 & 4.35 \\
\hline $\mathbf{2 0 1 7}$ & 4.03 & 4.33 \\
\hline $\mathbf{2 0 1 8}$ & 4.02 & 4.32 \\
\hline $\mathbf{2 0 1 9}$ & 4.03 & 4.32 \\
\hline $\mathbf{2 0 2 0}$ & 4.02 & 4.31 \\
\hline $\mathbf{2 0 2 1}$ & 4.02 & 4.32 \\
\hline $\mathbf{2 0 2 2}$ & 4.02 & 4.31 \\
\hline $\mathbf{2 0 2 3}$ & 4.02 & 4.32 \\
\hline $\mathbf{2 0 2 4}$ & 4.03 & 4.33 \\
\hline $\mathbf{2 0 2 5}$ & 4.02 & 4.32 \\
\hline
\end{tabular}




\begin{tabular}{|r|r|r|}
\hline Year & Minimum & Maximum \\
\hline $\mathbf{2 0 1 3}$ & 2.01 & 3.17 \\
\hline $\mathbf{2 0 1 4}$ & 1.98 & 3.18 \\
\hline $\mathbf{2 0 1 5}$ & 1.92 & 3.11 \\
\hline $\mathbf{2 0 1 6}$ & 1.89 & 3.15 \\
\hline $\mathbf{2 0 1 7}$ & 1.87 & 3.16 \\
\hline $\mathbf{2 0 1 8}$ & 1.81 & 3.11 \\
\hline $\mathbf{2 0 1 9}$ & 1.75 & 3.09 \\
\hline $\mathbf{2 0 2 0}$ & 1.65 & 3.04 \\
\hline $\mathbf{2 0 2 1}$ & 1.58 & 3.06 \\
\hline $\mathbf{2 0 2 2}$ & 1.55 & 3.04 \\
\hline $\mathbf{2 0 2 3}$ & 1.53 & 3.00 \\
\hline $\mathbf{2 0 2 4}$ & 1.51 & 2.96 \\
\hline $\mathbf{2 0 2 5}$ & 1.51 & 2.90 \\
\hline
\end{tabular}

Table 54. Percentage of benefits who moves to renewal results $(P B M R) .95 \%$ Confidence Interval. 


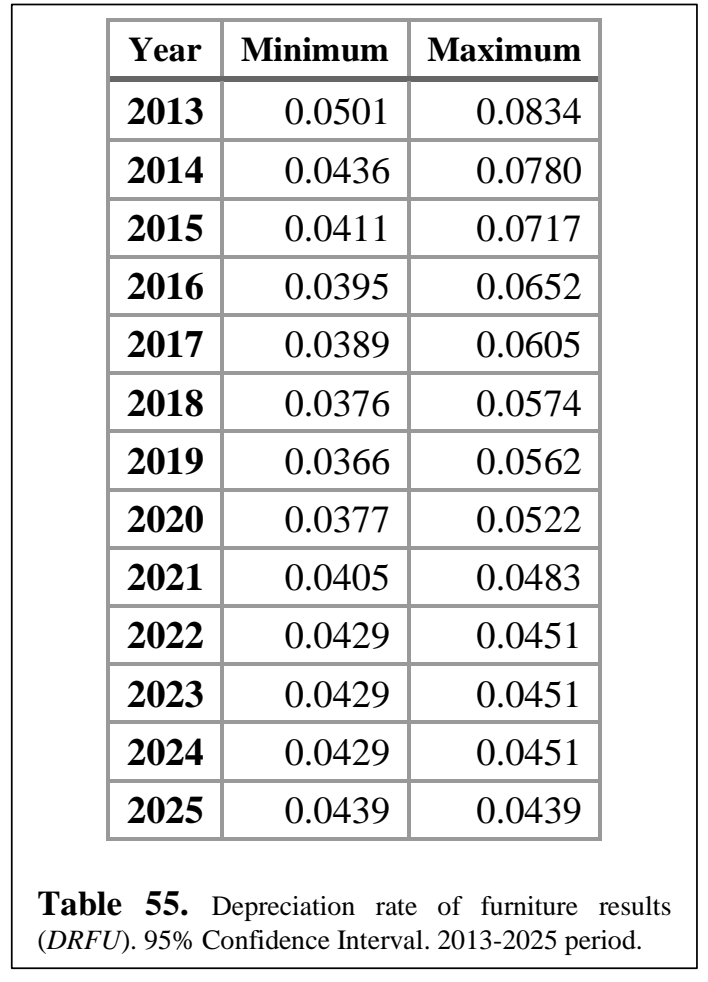




\begin{tabular}{|l|r|r|}
\hline Year & Minimum & Maximum \\
\hline $\mathbf{2 0 1 3}$ & 0.1994 & 0.2140 \\
\hline $\mathbf{2 0 1 4}$ & 0.2001 & 0.2121 \\
\hline $\mathbf{2 0 1 5}$ & 0.2001 & 0.2106 \\
\hline $\mathbf{2 0 1 6}$ & 0.1998 & 0.2106 \\
\hline $\mathbf{2 0 1 7}$ & 0.2000 & 0.2108 \\
\hline $\mathbf{2 0 1 8}$ & 0.1998 & 0.2110 \\
\hline $\mathbf{2 0 1 9}$ & 0.2009 & 0.2089 \\
\hline $\mathbf{2 0 2 0}$ & 0.1997 & 0.2098 \\
\hline $\mathbf{2 0 2 1}$ & 0.2009 & 0.2082 \\
\hline $\mathbf{2 0 2 2}$ & 0.2008 & 0.2085 \\
\hline $\mathbf{2 0 2 3}$ & 0.2001 & 0.2100 \\
\hline $\mathbf{2 0 2 4}$ & 0.2011 & 0.2086 \\
\hline $\mathbf{2 0 2 5}$ & 0.2020 & 0.2078 \\
\hline
\end{tabular}




\begin{tabular}{|l|l|r|}
\hline Year & Minimum & Maximum \\
\hline $\mathbf{2 0 1 3}$ & 0.011761 & 0.011761 \\
\hline $\mathbf{2 0 1 4}$ & 0.011034 & 0.011034 \\
\hline $\mathbf{2 0 1 5}$ & 0.010718 & 0.010718 \\
\hline $\mathbf{2 0 1 6}$ & 0.010627 & 0.010627 \\
\hline $\mathbf{2 0 1 7}$ & 0.010582 & 0.010582 \\
\hline $\mathbf{2 0 1 8}$ & 0.010566 & 0.010566 \\
\hline $\mathbf{2 0 1 9}$ & 0.010531 & 0.010531 \\
\hline $\mathbf{2 0 2 0}$ & 0.010539 & 0.010539 \\
\hline $\mathbf{2 0 2 1}$ & 0.010553 & 0.010553 \\
\hline $\mathbf{2 0 2 2}$ & 0.010517 & 0.010517 \\
\hline $\mathbf{2 0 2 3}$ & 0.010529 & 0.010529 \\
\hline $\mathbf{2 0 2 4}$ & 0.010588 & 0.010588 \\
\hline $\mathbf{2 0 2 5}$ & 0.010543 & 0.010543 \\
\hline
\end{tabular}

Table 57. Depreciation rate of property results (DRRE). 95\% Confidence Interval. 2013-2025 period. 


\begin{tabular}{|c|c|c|}
\hline Year & Minimum & Maximum \\
\hline 2013 & 3.02 & 3.74 \\
\hline 2014 & 2.99 & 3.67 \\
\hline 2015 & 3.01 & 3.70 \\
\hline 2016 & 3.00 & 3.72 \\
\hline 2017 & 2.99 & 3.71 \\
\hline 2018 & 3.02 & 3.71 \\
\hline 2019 & 2.98 & 3.68 \\
\hline 2020 & 2.96 & 3.65 \\
\hline 2021 & 2.97 & 3.66 \\
\hline 2022 & 3.02 & 3.73 \\
\hline 2023 & 3.02 & 3.70 \\
\hline 2024 & 3.01 & 3.69 \\
\hline 2025 & 3.00 & 3.72 \\
\hline
\end{tabular}




\title{
Appendix I. Model Variables and Forrester Diagram
}

\author{
Variables related with heritage \\ ASST Assets [€] \\ ASS0 Initial Assets [€] \\ EQUI Equity [€] \\ LIAB Liability $[€]$ \\ LIA0 Initial Liability [€]
}

Variables related with the Income

BFE1 Basic fee for three days of class per week [€]

BFE2 Basic fee for two days of class per week [€]

BFE3 Basic fee for one day of class per week [€]

BFE4 Basic fee for tutorials [€]

CFE1 Current fee for three days of class per week [ $€]$

CFE2 Current fee for two days of class per week [€]

CFE3 Current fee for one day of class per week $[€]$

CFE4 Current fee for tutorials [€]

QRSS Quarterly revenue from sales and services [€]

QST1 Quarterly students with type 1 fee [number]

QST2 Quarterly students with type 2 fee [number]

QST3 Quarterly students with type 3 fee [number]

QST4 Quarterly students with type 4 fee [number]

\section{Variables related with the Expense}

ACTE Annual council tax expense [€]

AINP Annual insurance premiums [€]

BSAW Base salary for worker [€]

DRFU Depreciation rate of furniture [ratio]

DRCO Depreciation rate of computers [ratio]

DRRE Depreciation rate of property [ratio]

FQAC Final quarterly Amortization of computers [ $€]$

FQAP Final quarterly Amortization of property $[€]$

FQFU Final quarterly furniture value $[€]$

IEPR Initial expenditure on property [€]

ISCO Initial spending on computers $[€]$

ISFU Initial spending on furniture [€]

IVCE Initial value of computer equipment to renew $[€]$

IVFRI Initial value of the furniture to renew [€]

IVPR Initial value of the property to renew $[€]$

OQEX Other quarterly expenses [ $€]$

QACO Quarterly Amortization of computer equipment $[€]$

QAFU Quarterly Amortization of furniture [€]

QAIN Quarterly amortization Insurance [€]

QAPR Quarterly Amortization of property [€]

QFCO Quarterly financial costs [€]

QSAC Quarterly salary costs [€]

QNWO Quarterly number of workers [people]

QPTM Quarterly purchases, training material $[€]$ 
QTAX Quarterly tax expense [€]

QTEX Quarterly total expenditure [€]

QWPC Quarterly Work performed by other companies $[€]$

REI1 Renewal of furniture [€]

REI2 Renewal of property [€]

REI3 Renewal of computers [€]

REIN Total quarterly Renewal $[€]$

SSCC Social security base (autonomous) quarterly [€]

SSCT Social security (autonomous) quarterly [€]

TQAM Total quarterly amortization [€]

TQSL Total quarterly spending on light $[€]$

TQSW Total quarterly spending on water $[€]$

Variables related with Profit

BRMR Benefits rate that moves to renewal [probability]

IPPS Initial part of the profit dedicated to creating savings [€]

PATQ Profit after tax for the year quarterly [€]

PBMR Percentage of benefits who moves to renewal $[€]$

PEDR Part of equity dedicated to renewal $[€]$

PIER Part of the initial equity dedicated to renewal [€]

PPSA Part of profit dedicated to creating savings [€]

PYBT Profit for the year before tax quarterly $[€]$

RCQU Rate cut quotas [probability]

Variables related with the Tax Agency

TA08 Input Quarterly Value-Added Tax 8\% [€]

TA21 Input Quarterly Value-Added Tax 21\% [€]

TAAG Tax Agency [€]

TAOU Output Quarterly Value-Added Tax [€]

TAPR Percentage $12 \%$ quarterly tax over profits [€]

TAX1 Percentage Tax type 1 for water [\%]

TAX2 Percentage Tax type 2 for general values [\%]

TAX3 Percentage Tax type 3 to apply to profits of an enterprise [\%] 


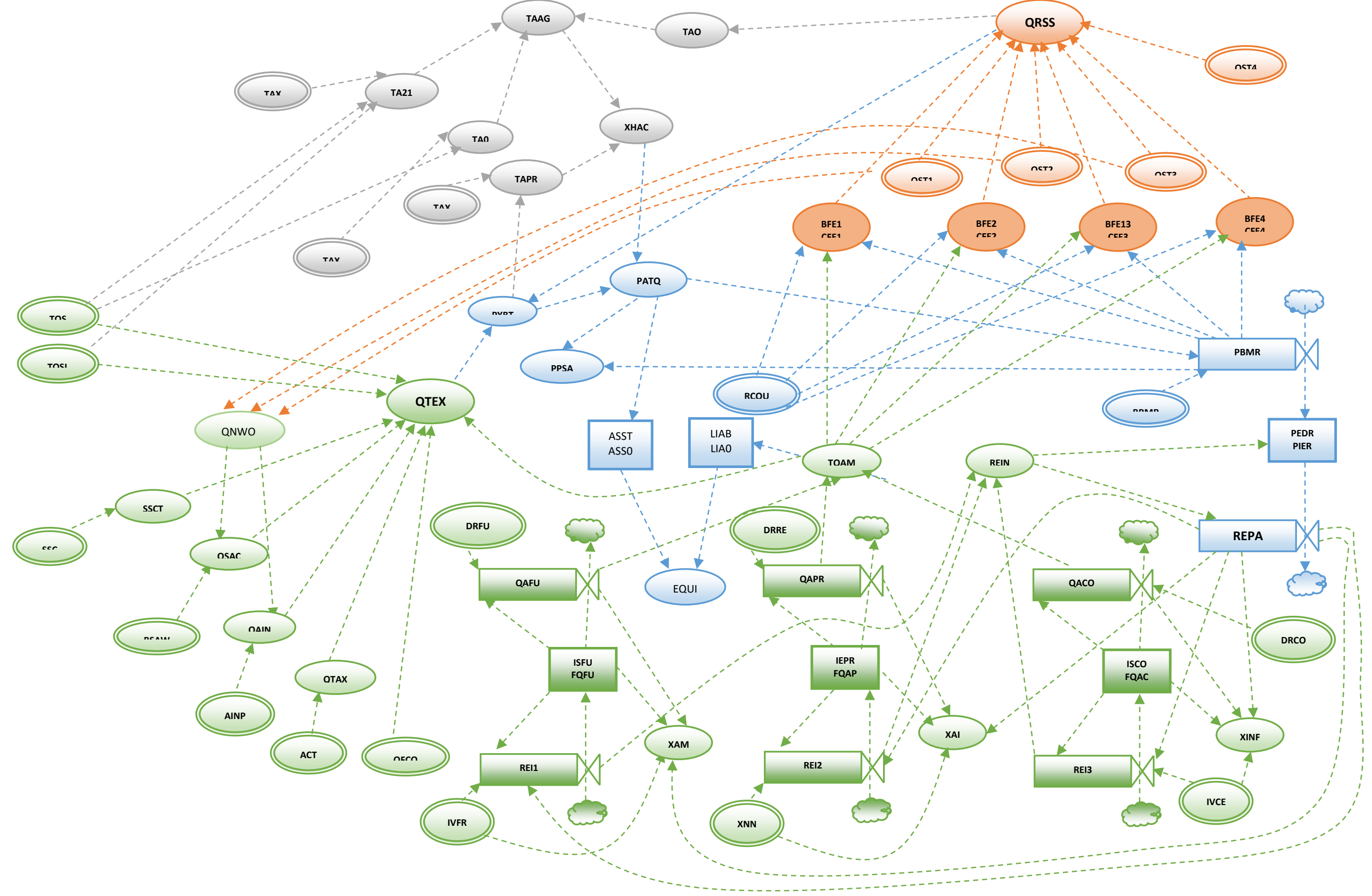


Figure 1: Forrester Diagram for the economical/mathematical model 


\section{Appendix II}

\section{Equations of the Model}

First the initial position of the business is observed.

The existing asset consists of the property, computer equipment and furniture, and has a total value of $€ 175,000$ (value of $A S S O$ ), of which $€ 150,000$ is a loan, which the liability is this amount (value of $L I A O$ ) and equity, EQUI, amounts at the beginning of the activity are $€ 25,000$.

The following equations are included in the model to observe how the asset, liability and equity range in each quarterly period.

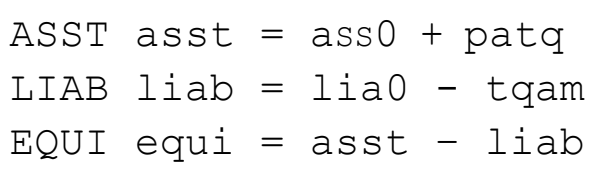

\section{Equations related with expenses}

Water, light, shopping, work done by other companies, insurance, financial expenses, no state taxes, employee salaries, social security, depreciation of property, furniture and equipment are considered as expenses.

Note that the number of company employees is calculated as the integer part of the result of dividing the total number of students at the school by 30 because it is considered that a teacher can deal with 30 students.

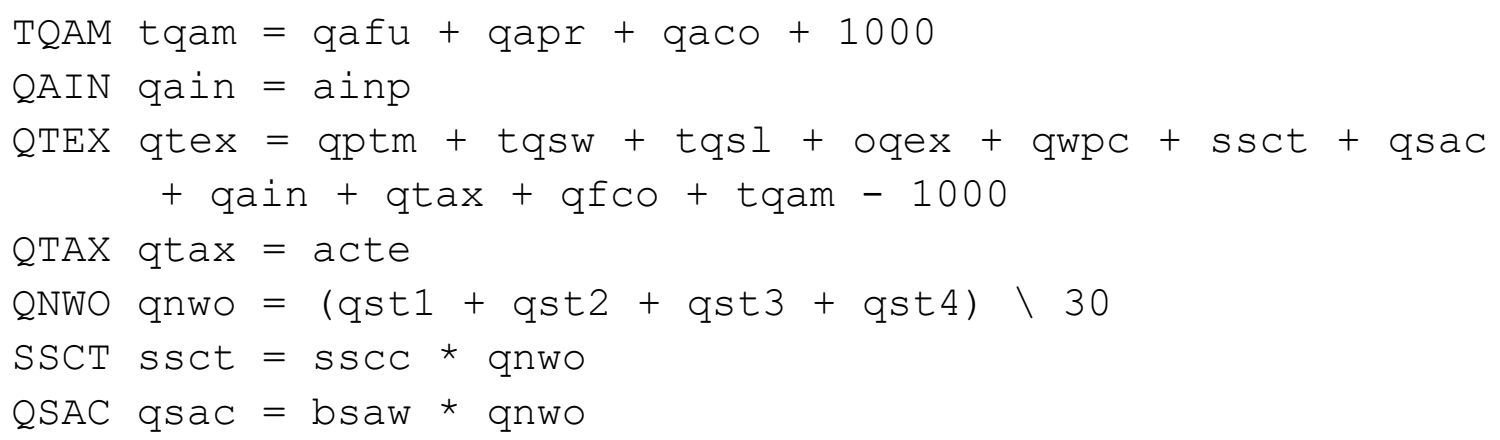


Also note that $€ 1000$ is added in TQAM and then this amount is subtracted in $Q T E X$.

Such $€ 1000$ refers to an upper limit mark after calculating quotas.

\section{Equations related with Tax Agency}

Here we look at the input VAT and output VAT.

We consider as input VAT that has been generated when spending (it is incorporated in the price of the purchased product). We use the VAT 6\% (2008) which evolved to $8 \%$ (year 2011) also VAT at $16 \%$ (2008) which evolved to $18 \%$ (in 2011) and $21 \%$ (in the third quarter of 2012).

The output VAT which is generated by the company and has evolved as the VAT of $16 \%$, $18 \%$ and $21 \%$

Also the tax of $12 \%$, which must be paid for profits, has been included in this section,

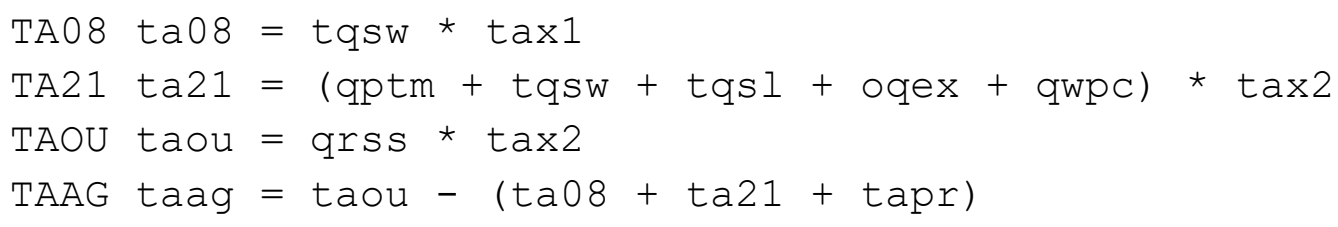

$T A A G$ is the result of output VAT minus input VAT. We should note that:

- If $T A A G$ is positive, the company pays to Tax Agency.

- If $T A A G$ is negative, Tax Agency returns paid taxes to the company.

\section{Equations related with Income}

In this small company there are four types of fees; it depends on the number of class hours that students hired. Besides, fees may be lowered by $0.1 \%$ on a quarterly if the percentage of quarterly profits which are moving into investment exceeds the total expense in amortization plus $€ 1000$ (those that are reflected in the equation that calculates TQAM). Otherwise, the fee should not be modified. This is reflected in the following algorithms. Note that capital letters correspond to the name of the variable that is calculated with the corresponding algorithm: 


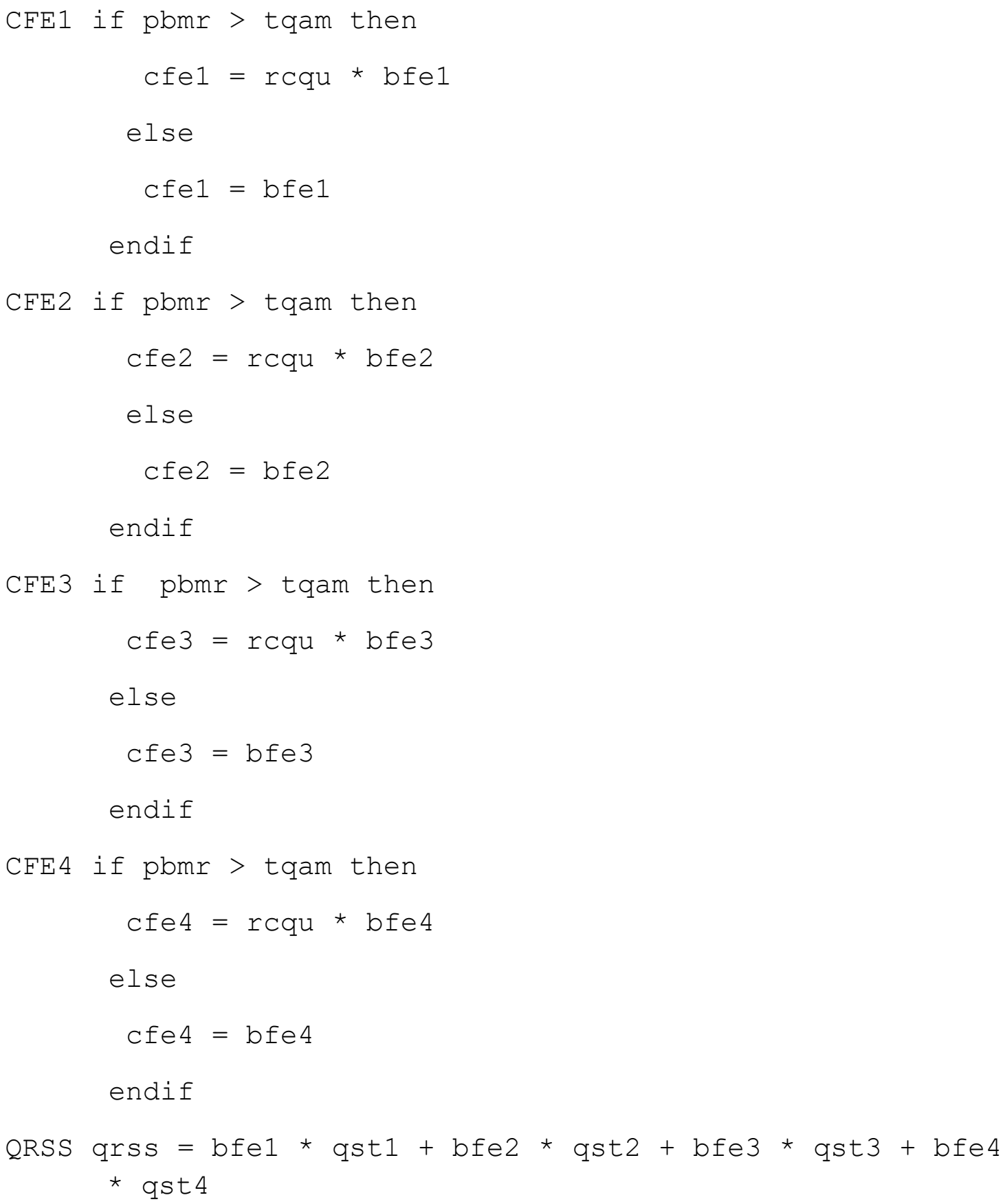

Equations related with quarterly amortizations of furniture, building and informatics equipment

Note that an amortization period of 10,50 and 5 years has been programmed for each type of good. When these periods finish, the following amounts will be used to renovate the respective goods:

- For computers: $€ 1000$. 
- $\quad$ For furniture: $€ 500$.

- For property: € 5000.

Such renewal will be financed with the existing capital for renovations. Thus, the depreciation and renewals are calculated as follows:

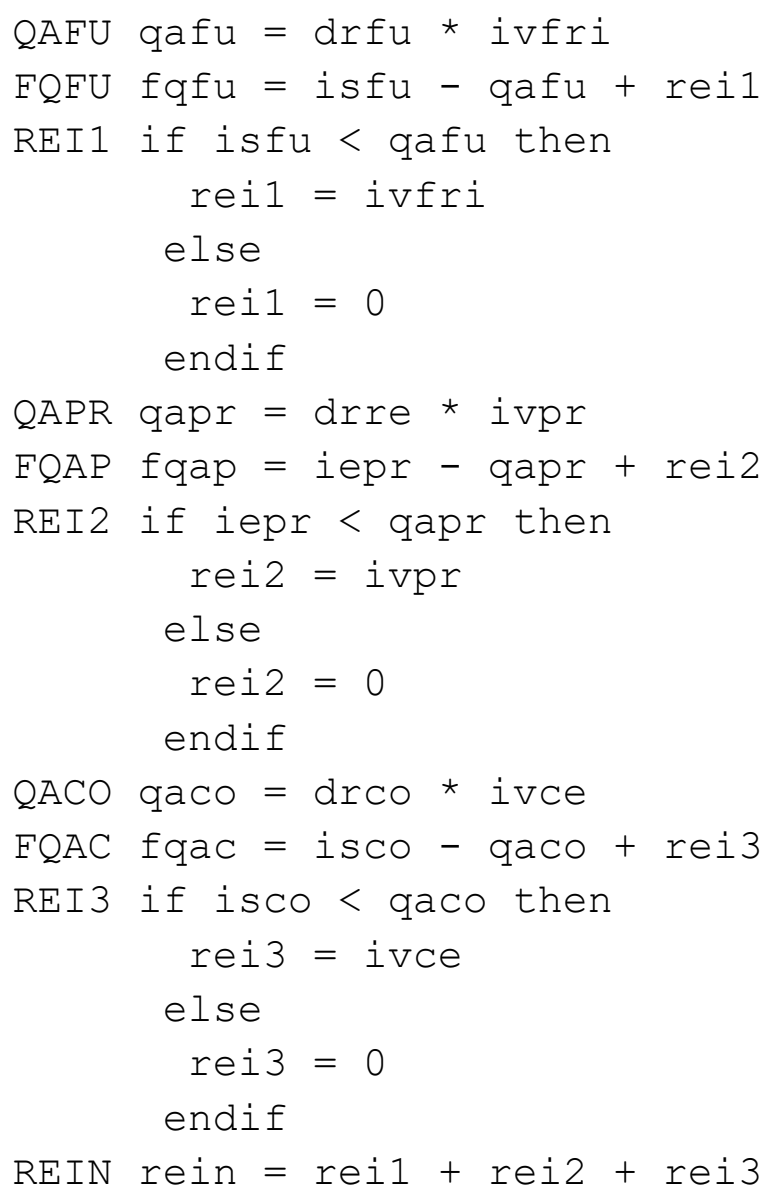

\section{Equations related with Profit}

Note that if there are some benefits in the company, $30 \%$ of them will be used to create a financial cushion and the remaining will be accumulated for possible future reinvestment in the business. Thus, capital for reinvestment will be distributed as follows: 
- If reinvestment is needed in one of three considered chapters (property, furniture and computer equipment), the capital for reinvestment should go entirely to this one.

- If reinvestment is needed in two of them, such capital should be split fifty-fifty.

- If reinvestment is needed in all of them, a third should be assigned each one.

This should be written in programming language as follows:

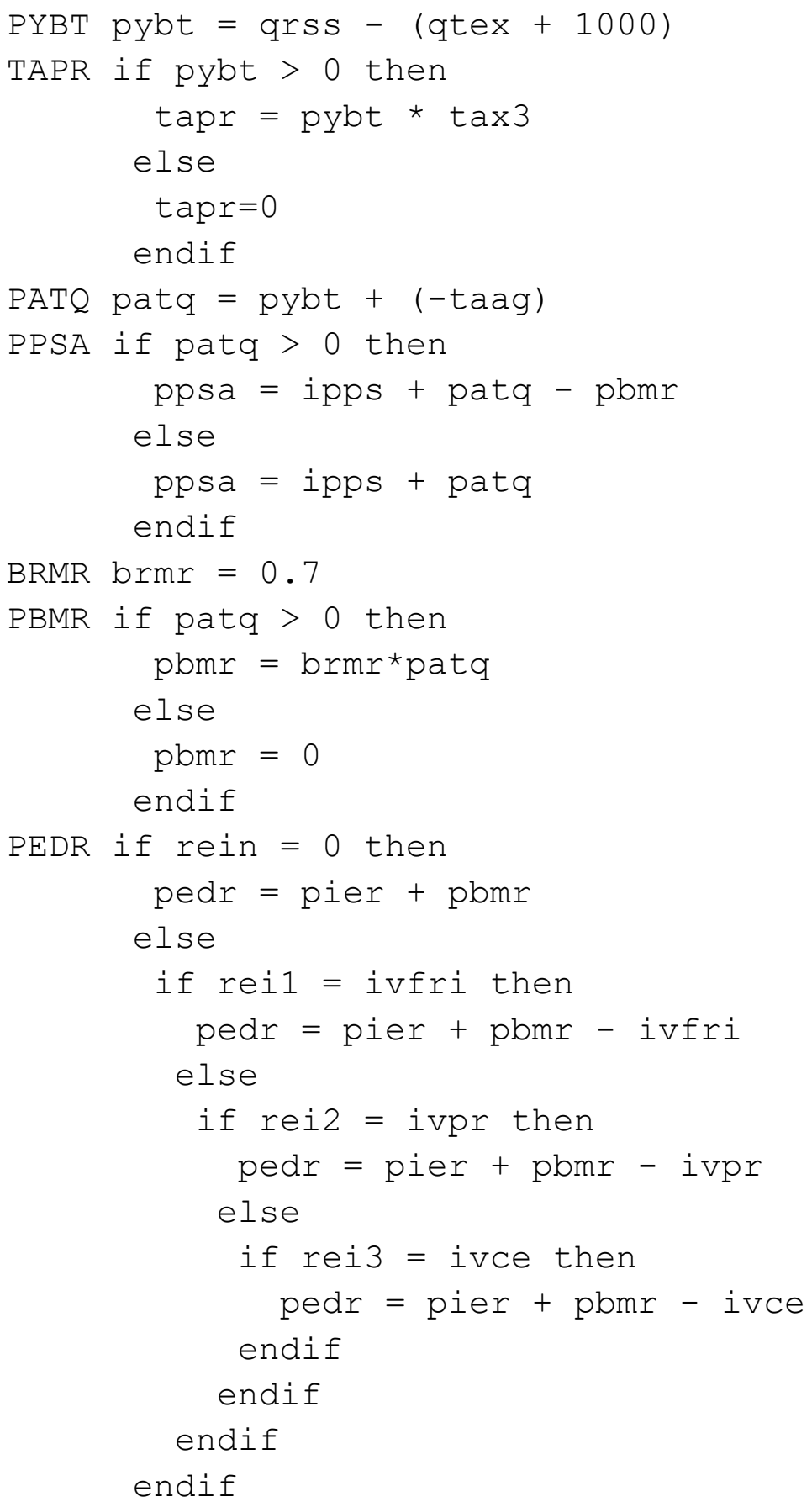




\section{Appendix III}

\section{Input variables in their stochastic formulation}

TQSW Total quarterly spending on water

$$
\operatorname{TQSW}(t)= \begin{cases}-1.42632+\frac{52}{1+0.474899 \mathrm{e}^{-1.02205(-2008+\mathrm{t})}} & \text { term } 1 \\ -5.99658+\frac{23}{1+0.331495 e^{-0.915049(-2008.25+\mathrm{t})}} & \text { term } 2 \\ -3.33509+\frac{55}{1+0.474495 e^{-0.885117(-2008.5+\mathrm{t})}} & \text { term } 3 \\ -1.70267-\frac{27}{1+0.450443 e^{-1.01076(-2008.75+\mathrm{t})}} & \text { term } 4\end{cases}
$$

First term,

\begin{tabular}{|l|l|l|l|l|}
\hline$\alpha$ & $\beta$ & $\gamma$ & $\delta$ & $\mu$ \\
\hline-1.42632 & 52 & 0.474899 & -1.02205 & 2008 \\
\hline C Matrix & Mean of transformed function & Estimation Error \\
\hline \multicolumn{2}{|c|}{$(0.0055061)$} & $\mathrm{T} 1=46.223568$ & $\mathrm{~S}=1.573375$ \\
\hline
\end{tabular}

Table 1. TQSW 1 Variable

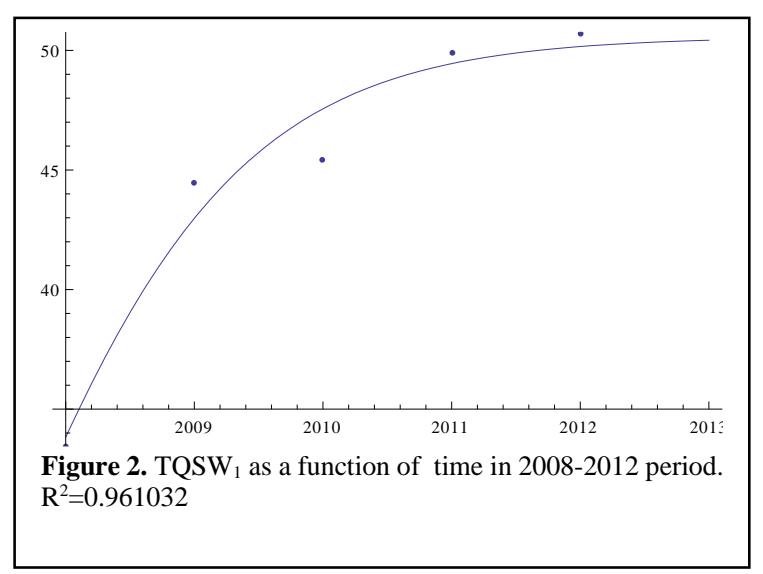


Second term,

\begin{tabular}{|l|l|l|l|l|}
\hline$\alpha$ & $\beta$ & $\gamma$ & $\delta$ & $\mu$ \\
\hline-5.99658 & 23 & 0.331495 & -0.915049 & 2008.25 \\
\hline C Matrix & Mean of transformed function & Estimation Error \\
\hline \multicolumn{2}{|r|}{$(0.048472266)$} & $T 1=20.948577$ & $S=0.523382$ \\
\hline
\end{tabular}

Table 2. TQSW 2 Variable

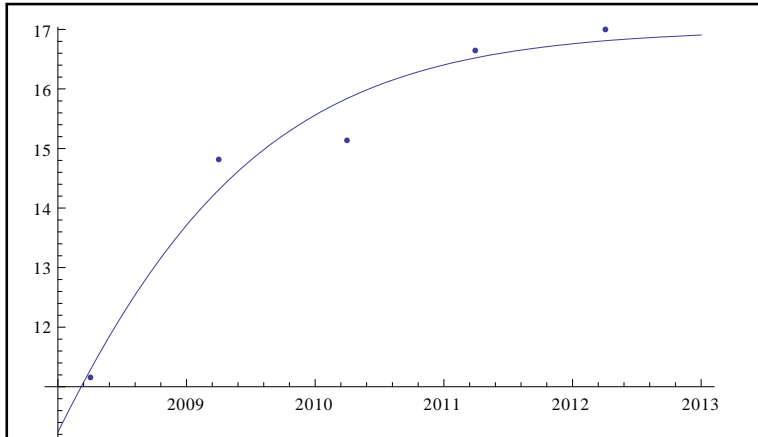

Figure 3. $\mathrm{TQSW}_{2}$ as a function of time in $2008-2012$ period. $\mathrm{R}^{2}=0.961899$.

Third term,

\begin{tabular}{|l|l|l|l|l|}
\hline$\alpha$ & $\beta$ & $\gamma$ & $\delta$ & $\mu$ \\
\hline-3.33509 & 55 & 0.474495 & -0.885117 & 2008.5 \\
\hline C Matrix & Mean of transformed function & Estimation Error \\
\hline \multicolumn{2}{|c|}{$(0.005189633)$} & $\mathrm{T} 1=48.332337$ & $\mathrm{~S}=1.700310$ \\
\hline
\end{tabular}

Table 3. $\mathrm{TQSW}_{3}$ Variable

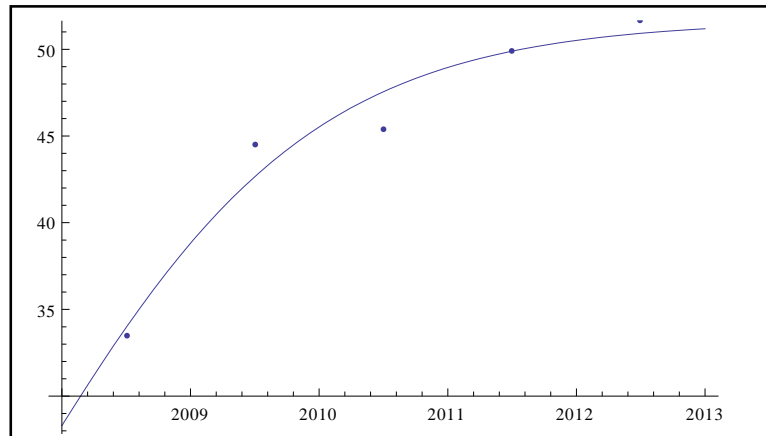

Figure 4. $\mathrm{TQSW}_{3}$ as a function of time in 2008-2012 period. $\mathrm{R}^{2}=0.957316$. 
Fourth term,

\begin{tabular}{|l|l|l|l|l|}
\hline$\alpha$ & $\beta$ & $\gamma$ & $\delta$ & $\mu$ \\
\hline-1.70267 & 27 & 0.450443 & -1.01076 & 2008.75 \\
\hline C Matrix & Mean of transformed function & Estimation Error \\
\hline \multicolumn{2}{|c|}{$(0.0220059)$} & $T 1=24.101295$ & $S=0.783738$ \\
\hline
\end{tabular}

Table 4. $\mathrm{TQSW}_{4}$ Variable

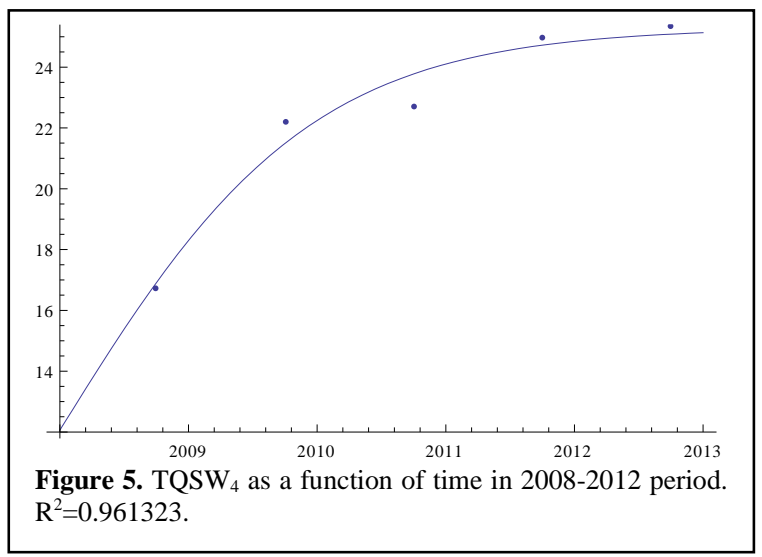

\section{QFCO Quarterly financial costs}

$$
\begin{array}{r}
q f \operatorname{co}(t)=-14.2903+\frac{35}{1+2.65463 e^{-1.06623(-2010.25+\mathrm{t})}} \\
+\frac{25}{1+9.27027 \times 10-7 e^{3.75051(-2008+\mathrm{t})}}
\end{array}
$$

\begin{tabular}{|l|l|l|l|l|}
\hline$\alpha$ & $\beta_{1}$ & $\gamma_{1}$ & $\delta_{1}$ & $\mu_{1}$ \\
\hline-14.2903 & 35 & 2.65463 & -1.06623 & 2010.25 \\
\hline & $\beta_{2}$ & $\gamma_{2}$ & $\delta_{2}$ & $\mu_{2}$ \\
\hline & 25 & $9.27 \cdot 10^{-7}$ & 3.75051 & 2008 \\
\hline C Matrix & \multicolumn{2}{|l|}{ Mean of transformed function } & Estimation Error \\
\hline$\left(\begin{array}{ll}0.02771956 \\
0.00268491 & 0.00268491\end{array}\right)$ & $\begin{array}{l}\mathrm{T} 1=12.753452 \\
\mathrm{~T} 2=19.128360\end{array}$ & $\mathrm{~S}=4.665131$ \\
\hline
\end{tabular}

Table 5. QFCO Variable

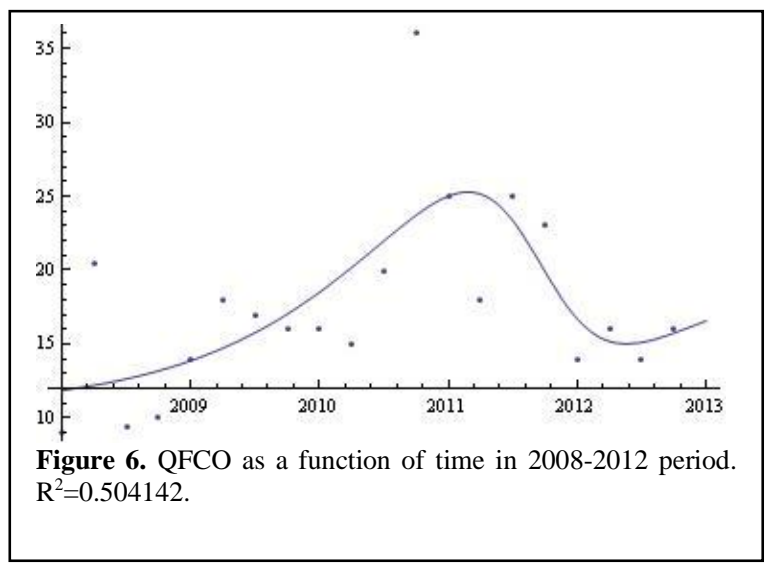


ACTE Annual council tax expense

There is no annual trend observed. Thus, the trend is studied quarterly.

$$
\operatorname{acte}(t)= \begin{cases}0 & \text { term } 1 \\ 31.8197+\frac{100}{1+761.108 e^{-2.11399(-2008.25+\mathrm{t})}} & \text { term } 2 \\ \frac{115}{1+2959.9 e^{-7.55107(-2008.5+\mathrm{t})}} & \text { term } 3 \\ 9.4325+\frac{110}{1+1.94299 \times 10-14 e^{29.336(-2008.75+\mathrm{t})}} & \text { term } 4\end{cases}
$$

Second term,

\begin{tabular}{|l|l|l|l|l|}
\hline$\alpha$ & $\beta$ & $\gamma$ & $\delta$ & $\mu$ \\
\hline 31.8197 & 100 & 761.108 & -2.11399 & 2008.25 \\
\hline C Matrix & Mean of transformed function & Estimation Error \\
\hline \multicolumn{2}{|r|}{$(0.000182493598)$} & $\mathrm{T} 1=27.655123$ & $\mathrm{~S}=31.202546$ \\
\hline
\end{tabular}

Table 6. ACTE 2 Variable

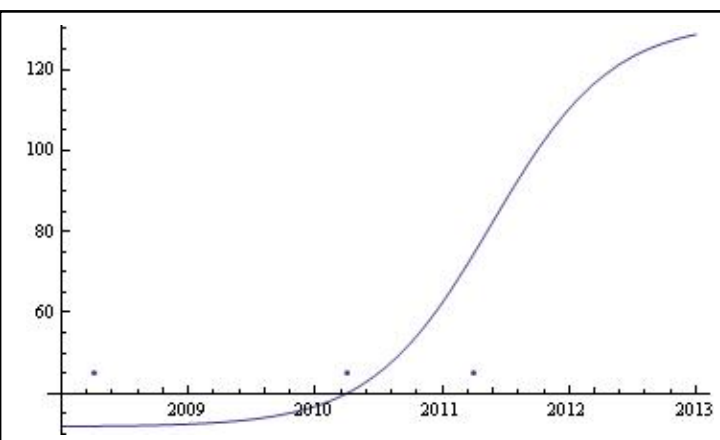

Figure 7. $\mathrm{ACTE}_{2}$ as a function of time in 2008-2012 period. $\mathrm{R}^{2}=0.802051$

Third term,

\begin{tabular}{|l|l|l|l|l|}
\hline$\alpha$ & $\beta$ & $\gamma$ & $\delta$ & $\mu$ \\
\hline 0 & 115 & 2956.89 & -7.55006 & 2008.5 \\
\hline C Matrix & Mean of transformed function & Estimation Error \\
\hline \multicolumn{2}{|c|}{$(0.000023993272)$} & $T 1=77.988927$ & $S=0.052593$ \\
\hline
\end{tabular}

Table 7. $\mathrm{ACTE}_{3}$ Variable

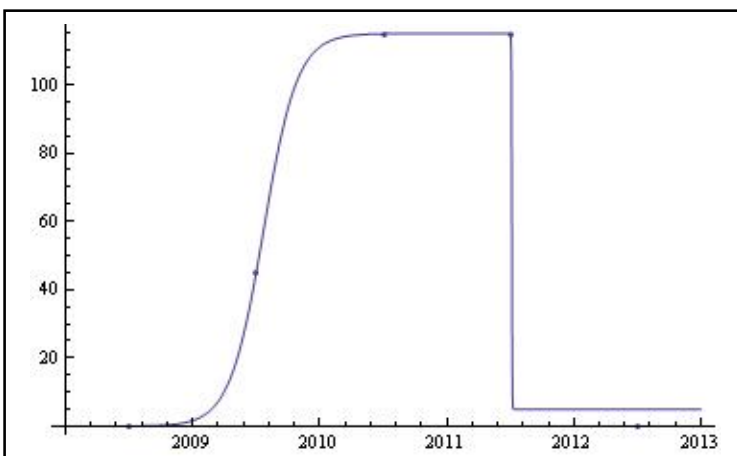

Figure 8. $\mathrm{ACTE}_{3}$ as a function of time in 2008-2012 period. $\mathrm{R}^{2}=0.998892$. 
Fourth term,

\begin{tabular}{|l|l|l|l|l|}
\hline$\alpha$ & $\beta$ & $\gamma$ & $\delta$ & $\mu$ \\
\hline 9.4325 & 110 & $1.94299 \cdot 10^{-14}$ & 29.336 & 2008.75 \\
\hline C Matrix & Mean of transformed function & Estimation Error \\
\hline \multicolumn{2}{|c|}{$(0.000075711117)$} & T1=41.875500 & $S=22.108790$ \\
\hline
\end{tabular}

Table 8. $\mathrm{ACTE}_{4}$ Variable

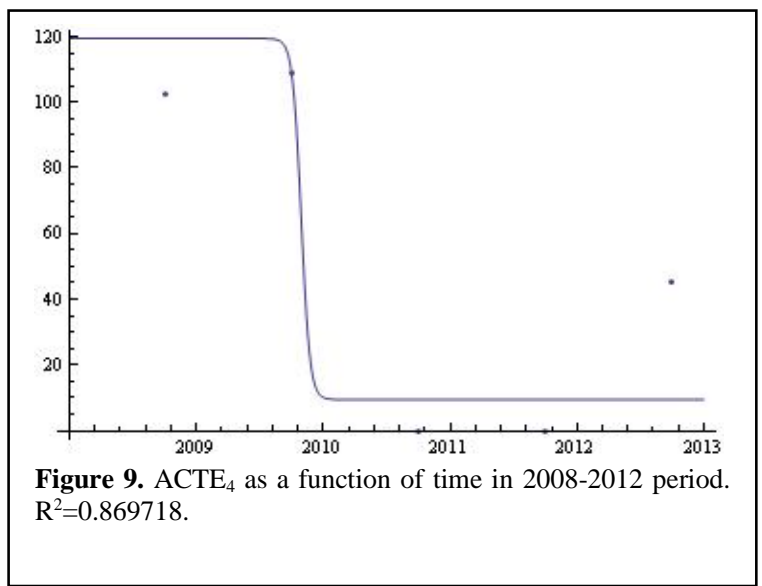

OQEX Other quarterly expenses

$$
\operatorname{oqex}(t)= \begin{cases}427.56+\frac{1100}{1+0.538236 e^{1.74555(-2008+\mathrm{t})}} & \text { term } 1 \\ 144.348+\frac{400}{1+0.687859 e^{1.66073(-2008.25+\mathrm{t})}} & \text { term } 2 \\ 425.137+\frac{1200}{1+0.671446 e^{1.63431(-2008.5+\mathrm{t})}} & \text { term } 3 \\ 215.702+\frac{580}{1+0.628745 e^{1.69208(-2008.75+\mathrm{t})}} & \text { term } 4\end{cases}
$$

First term,

\begin{tabular}{|l|l|l|l|l|}
\hline$\alpha$ & $\beta$ & $\gamma$ & $\delta$ & $\mu$ \\
\hline 427.56 & 1100 & 0.538236 & 1.74555 & 2008 \\
\hline C Matrix & \multicolumn{2}{|l|}{ Mean of transformed function } & Estimation Error \\
\hline \multicolumn{2}{|r|}{$(0.000002743680)$} & $T 1=211.212694$ & $S=12.795513$ \\
\hline
\end{tabular}

Table 9. $\mathrm{OQEX}_{1}$ Variable

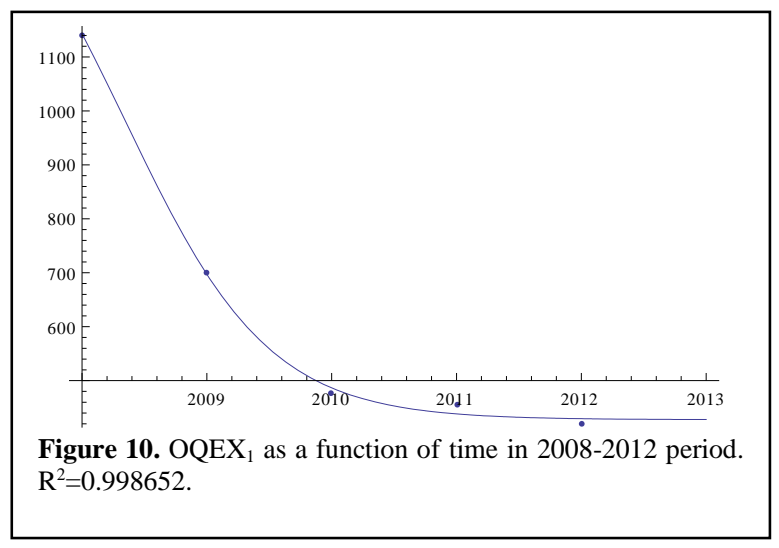


Second term,

\begin{tabular}{|l|l|l|l|l|}
\hline$\alpha$ & $\beta$ & $\gamma$ & $\delta$ & $\mu$ \\
\hline 144.348 & 400 & 0.687859 & 1.66073 & 2008.25 \\
\hline \multicolumn{2}{|l|}{ Covariance Matrix } & Mean of transformed function & Estimation Error \\
\hline \multicolumn{2}{|r|}{$(0.000025112120)$} & \multicolumn{2}{|l|}{ T1=69.642562 } & $\mathrm{S}=4.162523$ \\
\hline
\end{tabular}

Table 10. OQEX 2 Variable

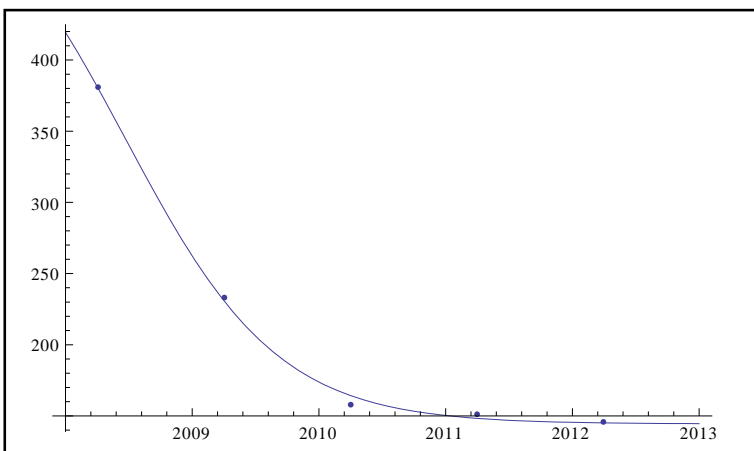

Figure 11. $\mathrm{OQEX}_{2}$ as a function of time in 2008-2012 period.

$\mathrm{R}^{2}=0.998692$.

Third term,

\begin{tabular}{|l|l|l|l|l|}
\hline$\alpha$ & $\beta$ & $\gamma$ & $\delta$ & $\mu$ \\
\hline 425.137 & 1200 & 0.671446 & 1.63431 & 2008.5 \\
\hline C Matrix & \multicolumn{2}{|l|}{ Mean of transformed function } & Estimation Error \\
\hline \multicolumn{2}{|l|}{$(0.000002743126)$} & $T 1=213.635989$ & $S=13.605470$ \\
\hline
\end{tabular}

Table 11. OQEX 3 Variable

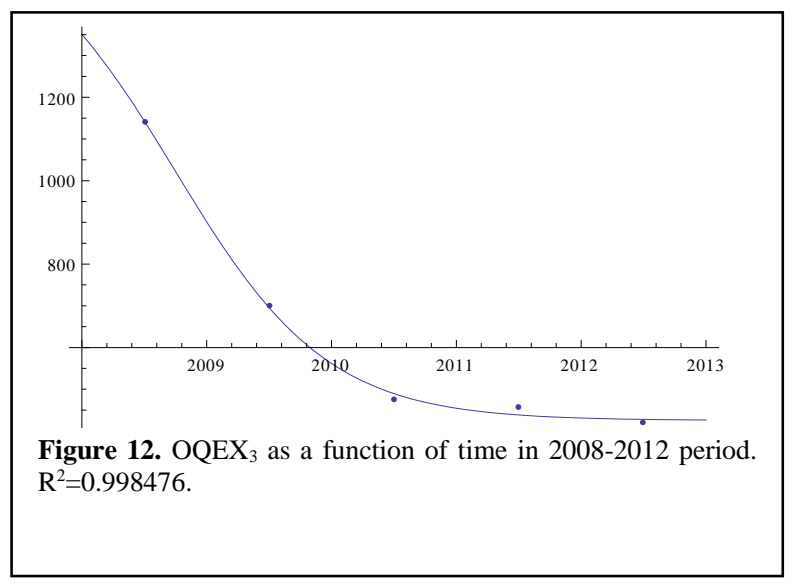


Fourth term,

\begin{tabular}{|l|l|l|l|l|}
\hline$\alpha$ & $\beta$ & $\gamma$ & $\delta$ & $\mu$ \\
\hline 215.702 & 580 & 0.628745 & 1.69208 & 2008.75 \\
\hline C Matrix & Mean of transformed function & Estimation Error \\
\hline \multicolumn{2}{|r|}{$(0.000011100548)$} & T1=104.784748 & $S=5.963226$ \\
\hline
\end{tabular}

Table 12. OQEX 4 Variable

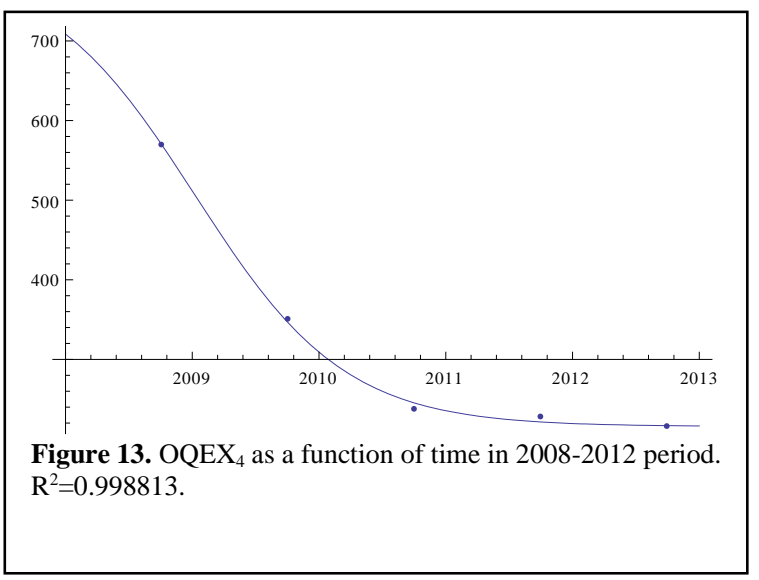

\section{AINP Annual insurance premiums}

$$
\operatorname{ainp}(t)=\left\{\begin{array}{lr}
\frac{150}{1+2879.7 \mathrm{e}^{-2.55069(-2008+\mathrm{t})}} & \text { term } 1 \\
23.5519+\frac{500}{1+39.7638 e^{-2.38296(-2008.25+\mathrm{t})}} & \text { term } 2 \\
285.069+\frac{800}{1+14.0268 e^{-0.879185(-2008.5+\mathrm{t})}} & \text { term } 3 \\
94.8596-\frac{100}{1+23317.5 e^{-6.4834(-2008.75+\mathrm{t})}} & \text { term } 4
\end{array}\right.
$$

First term,

\begin{tabular}{|l|l|l|l|l|}
\hline$\alpha$ & $\beta$ & $\gamma$ & $\delta$ & $\mu$ \\
\hline 0 & 150 & 2879.7 & 2.55069 & 2008 \\
\hline C Matrix & Mean of transformed function & Estimation Error \\
\hline \multicolumn{2}{|c|}{$(0.000044548553)$} & $T 1=41.537304$ & $\mathrm{~S}=74.515881$ \\
\hline
\end{tabular}

Table 13. AINP ${ }_{1}$ Variable

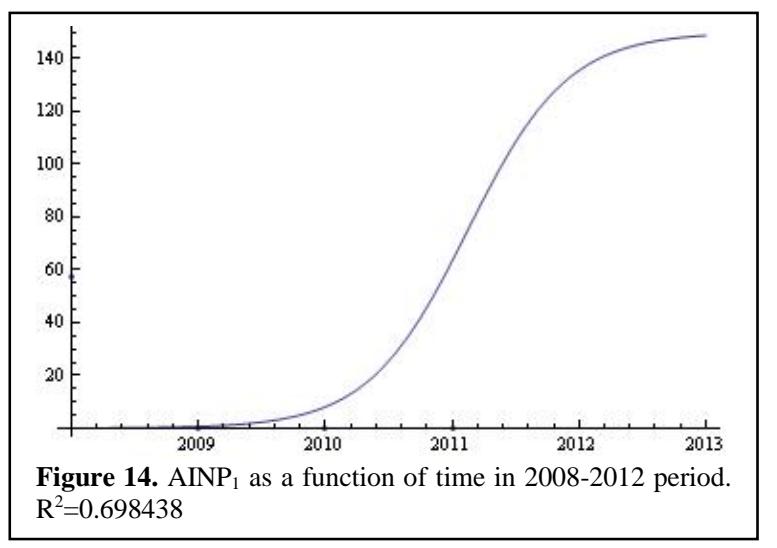


Second term,

\begin{tabular}{|l|l|l|l|l|}
\hline$\alpha$ & $\beta$ & $\gamma$ & $\delta$ & $\mu$ \\
\hline 23.5519 & 500 & 39.7638 & 2.38296 & 2008.25 \\
\hline C Matrix & Mean of transformed function & Estimation Error \\
\hline \multicolumn{2}{|c|}{$(0.000005027678)$} & T1=295.258053 & $S=71.174843$ \\
\hline
\end{tabular}

Table 14. $\mathrm{AINP}_{2}$ Variable

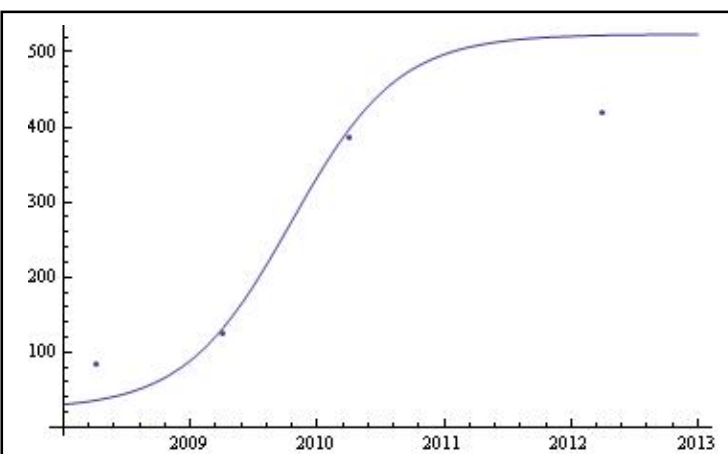

Figure 15. $\mathrm{AINP}_{2}$ as a function of time in 2008-2012 period. $\mathrm{R}^{2}=0.912327$.

Third term,

\begin{tabular}{|l|l|l|l|l|}
\hline$\alpha$ & $\beta$ & $\gamma$ & $\delta$ & $\mu$ \\
\hline 285.069 & 800 & 14.0268 & 0.879185 & 2008.5 \\
\hline C Matrix & \multicolumn{2}{|l|}{ Mean of transformed function } & Estimation Error \\
\hline \multicolumn{2}{|r|}{$(0.000005709743)$} & \multicolumn{2}{|l|}{$T 1=273.735162$} & $\mathrm{~S}=63.530681$ \\
\hline
\end{tabular}

Table 15. $\mathrm{AINP}_{3}$ Variable

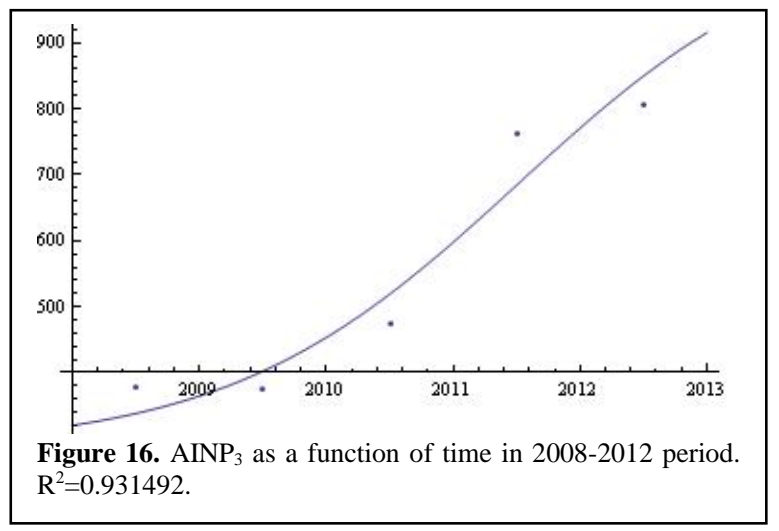


Fourth term,

\begin{tabular}{|l|l|l|l|l|}
\hline$\alpha$ & $\beta$ & $\gamma$ & $\delta$ & $\mu$ \\
\hline 94.8596 & -100 & 23317.5 & 6.4834 & 2008.75 \\
\hline C Matrix & Mean of transformed function & Estimation Error \\
\hline \multicolumn{2}{|c|}{$(0.000088566615)$} & T1=59.511622 & $S=4.681471$ \\
\hline
\end{tabular}

Table 16. $\mathrm{AINP}_{4}$ Variable

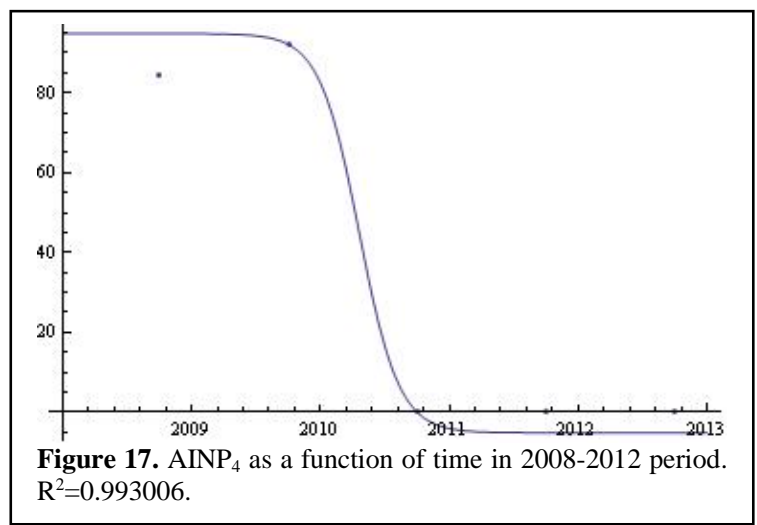

\section{SSCC Social security base (freelance) quarterly}

$$
\operatorname{sscc}(t)=\frac{760}{1+0.000513795 e^{-15.6765(-2009.75+\mathrm{t})}}+\frac{562}{1+1.5049 \cdot 10^{-9} e^{16.5377(-2008+\mathrm{t})}}
$$

\begin{tabular}{|l|l|l|l|l|}
\hline$\alpha$ & $\beta_{1}$ & $\gamma_{1}$ & $\delta_{1}$ & $\mu_{1}$ \\
\hline 0 & 760 & 0.000513795 & -15.6765 & 2010.75 \\
\hline & $\beta_{2}$ & $\gamma_{2}$ & $\delta_{2}$ & $\mu_{2}$ \\
\hline & 562 & 1.5049 & 16.5377 & 2008 \\
\hline C Matrix & $\begin{array}{l}\text { Mean of transformed } \\
\text { function }\end{array}$ & $\begin{array}{l}\text { Estimation } \\
\text { Error }\end{array}$ \\
\hline$\left(\begin{array}{cc}0.000000122529 & -0.000000006618 \\
-0.000000006618 & 0.000000618200\end{array}\right)$ & $\begin{array}{l}\mathrm{T} 1=548105038 \\
\mathrm{~T} 2=151740993\end{array}$ & $\mathrm{~S}=4.903342$ \\
\hline
\end{tabular}

Table 17. SSCC Variable

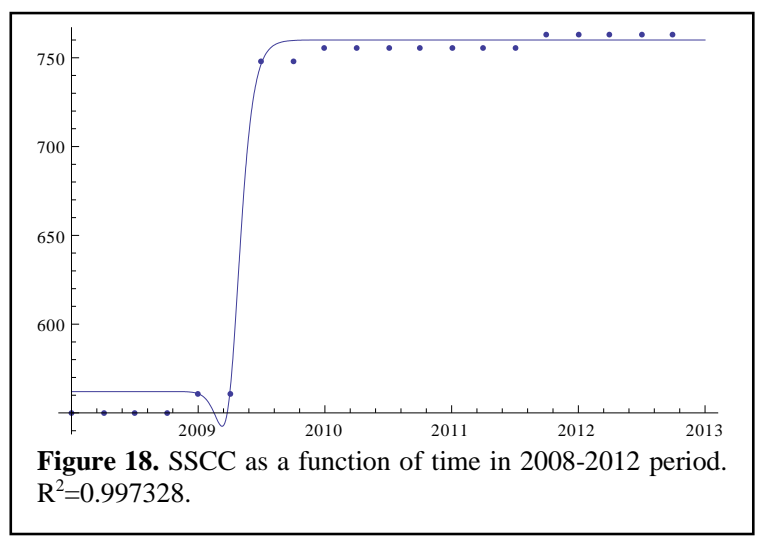


BSAW Base salary (employed)

$$
\begin{gathered}
\operatorname{bsaw}(t)=\frac{650}{1+30.4991 e^{-0.0512281(-2010.75+\mathrm{t})}}+\frac{620}{1+0.0179502 e^{-1.14956(-2009.75+\mathrm{t})}} \\
+\frac{600}{1+15.6752 e^{3.46454(-2008+\mathrm{t})}}
\end{gathered}
$$

\begin{tabular}{|l|l|l|l|l|}
\hline$\alpha$ & $\beta_{1}$ & $\gamma_{1}$ & $\delta_{1}$ & $\mu_{1}$ \\
\hline 0 & 650 & 30.4991 & -0.0512281 & 2010.75 \\
\hline & $\beta_{2}$ & $\gamma_{2}$ & $\delta_{2}$ & $\mu_{2}$ \\
\hline & 620 & 0.0179502 & -1.14956 & 2009.75 \\
\hline & $\beta_{3}$ & $\gamma_{3}$ & $\delta_{3}$ & $\mu_{3}$ \\
\hline \multicolumn{2}{l}{600} & 15.6752 & 3.46454 & 2008 \\
\hline C Matrix & $\begin{array}{l}\text { Mean of transformed } \\
\text { function }\end{array}$ & $\begin{array}{l}\text { Estimation } \\
\text { Error }\end{array}$ \\
\hline$\left(\begin{array}{ccc}0.056794 & -0.001916 & 0.0014336 \\
-0.001916 & 0.000064 & -0.0000517 \\
0.0014336 & -0.0000517 & 0.000737\end{array}\right)$ & $\begin{array}{l}\mathrm{T} 1=20.305313 \\
\mathrm{~T} 2=604.558224 \\
\mathrm{~T} 3=3.162605\end{array}$ & $\mathrm{~S}=3.891826$ \\
\hline
\end{tabular}

Table 18. BSAW Variable

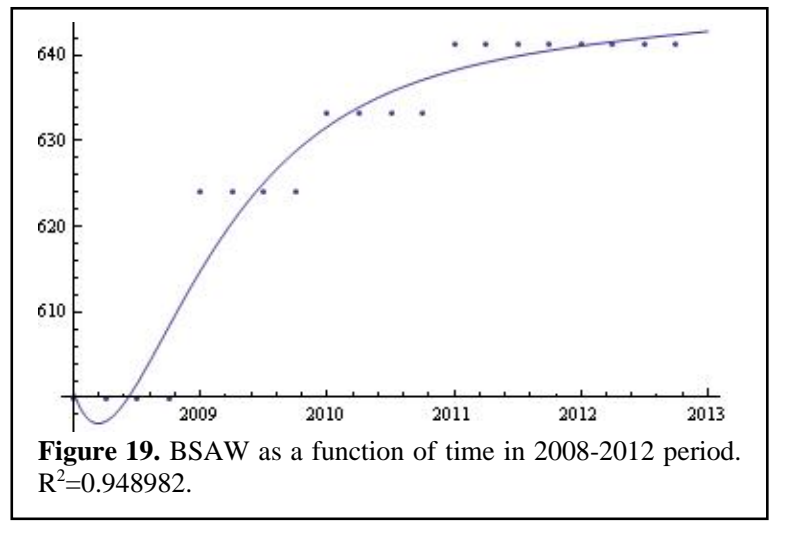


TQSL Total quarterly spending on light

$$
\operatorname{tqsl}(t)= \begin{cases}-7.47817+\frac{200}{1+0.296665 e^{-1.39606(-2008+\mathrm{t})}} & \text { term } 1 \\ -2.43371+\frac{67}{1+0.303852 e^{-1.30708(-2008.25+\mathrm{t})}} & \text { term } 2 \\ -3.486+\frac{196}{1+0.304488 e^{-1.40082(-2008.5+\mathrm{t})}} & \text { term } 3 \\ -4.83149+\frac{102}{1+0.302872 e^{-1.26019(-2008.75+\mathrm{t})}} & \text { term 4 }\end{cases}
$$

First term,

\begin{tabular}{|l|l|l|l|l|}
\hline$\alpha$ & $\beta$ & $\gamma$ & $\delta$ & $\mu$ \\
\hline-1.42632 & 52 & 0.474899 & -1.02205 & 2008 \\
\hline C Matrix & Mean of transformed function & Estimation Error \\
\hline \multicolumn{2}{|c|}{$(0.000679315686)$} & $T 1=187.173422$ & $\mathrm{~S}=0.841035$ \\
\hline
\end{tabular}

Table 19. TQSL $L_{1}$ Variable

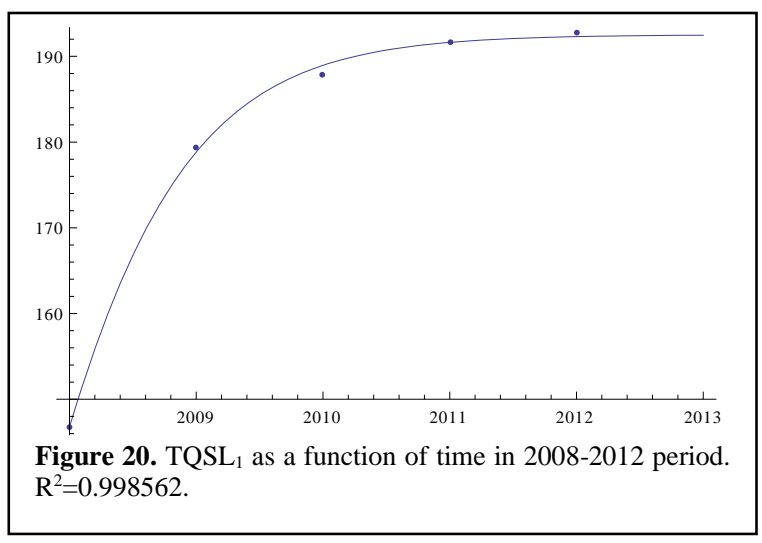

Second term,

\begin{tabular}{|l|l|l|l|l|}
\hline$\alpha$ & $\beta$ & $\gamma$ & $\delta$ & $\mu$ \\
\hline-5.99658 & 23 & 0.331495 & -0.915049 & 2008.25 \\
\hline C Matrix & Mean of transformed function & Estimation Error \\
\hline \multicolumn{2}{|l|}{$(0.005910408044)$} & $\mathrm{T} 1=62.465461$ & $\mathrm{~S}=0.484110$ \\
\hline
\end{tabular}

Table 20. $\mathrm{TQSL}_{2}$ Variable

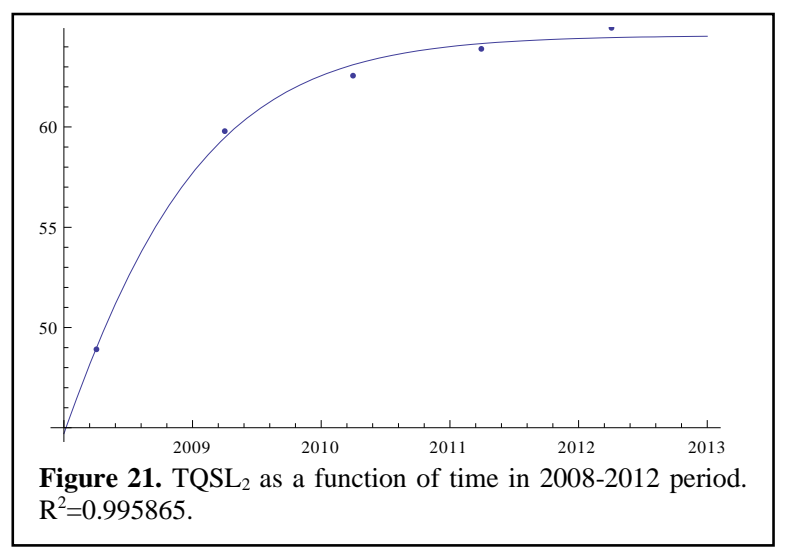


Third term,

\begin{tabular}{|l|l|l|l|l|}
\hline$\alpha$ & $\beta$ & $\gamma$ & $\delta$ & $\mu$ \\
\hline-3.33509 & 55 & 0.474495 & -0.885117 & 2008.5 \\
\hline C Matrix & Mean of transformed function & Estimation Error \\
\hline \multicolumn{2}{|c|}{$(0.000679344089)$} & $\mathrm{T} 1=183.181246$ & $\mathrm{~S}=0.845762$ \\
\hline
\end{tabular}

Table 21. $\mathrm{TQSL}_{3}$ Variable

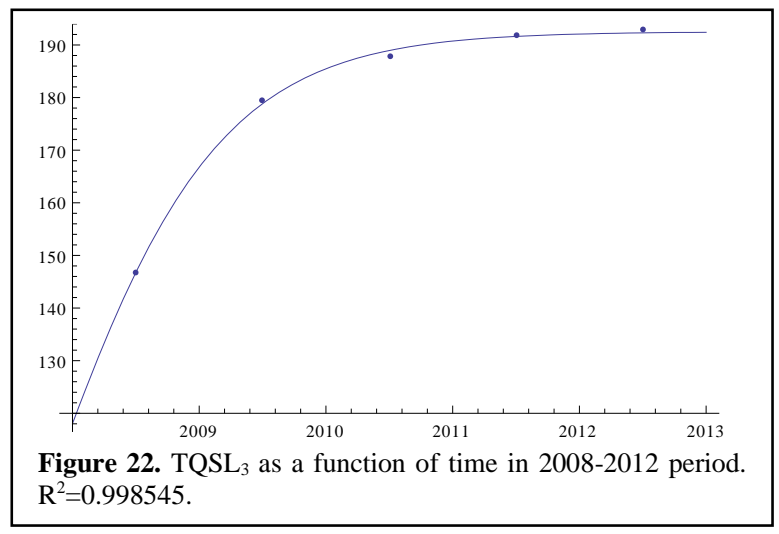

Fourth term,

\begin{tabular}{|l|l|l|l|l|}
\hline$\alpha$ & $\beta$ & $\gamma$ & $\delta$ & $\mu$ \\
\hline-1.70267 & 27 & 0.450443 & -1.01076 & 2008.75 \\
\hline C Matrix & Mean of transformed function & Estimation Error \\
\hline \multicolumn{2}{|c|}{$(0.002582147545)$} & $T 1=94.979113$ & $S=0.901404$ \\
\hline
\end{tabular}

Table 22. $\mathrm{TQSL}_{4}$ Variable

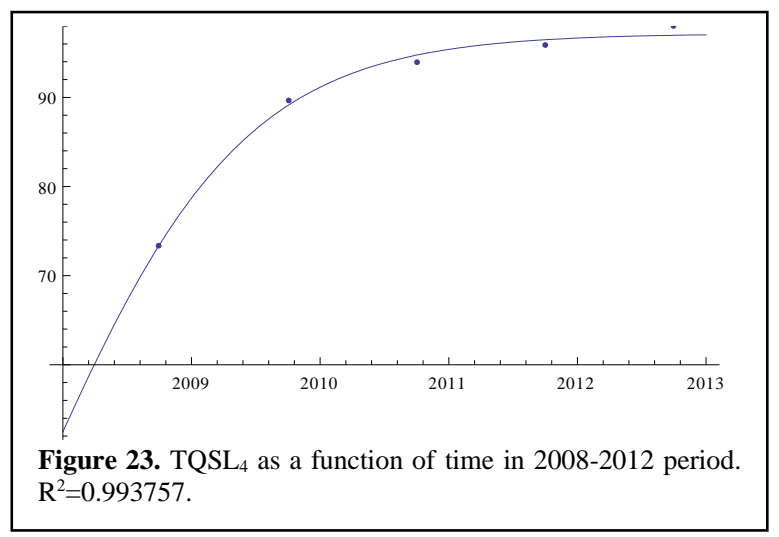




\section{QST1 Quarterly students with quota type 1}

$$
\begin{aligned}
& q s t 1(t) \\
& = \begin{cases}0.206398+\frac{20}{1+1.04564 \mathrm{e}^{-1.3813(-2008+\mathrm{t})}} & \text { term } 1 \\
\frac{14}{1+4.72 \cdot 10^{-12} e^{26.746(-2010.25+\mathrm{t})}+\frac{18}{1+11.0001 e^{-0.894831(-2008.25+\mathrm{t})}}} & \text { term } 2 \\
\frac{23^{8.90}}{1+0.243724 e^{81.94(-2011.5+\mathrm{t})}}+\frac{30}{1+13.2678 e^{-0.655784(-2008.5+\mathrm{t})}} & \text { term } 3 \\
\frac{14}{1+0.76041 e^{3.92966(-2010.75+\mathrm{t})}}+\frac{18}{1+8.32083 e^{-0.727505(-2008.75+\mathrm{t})}} & \text { term } 4\end{cases}
\end{aligned}
$$

First term,

\begin{tabular}{|l|l|l|l|l|}
\hline$\alpha$ & $\beta$ & $\gamma$ & $\delta$ & $\mu$ \\
\hline 0.206398 & 20 & 1.04564 & -1.3813 & 2008 \\
\hline C Matrix & Mean of transformed function & Estimation Error \\
\hline \multicolumn{2}{|c|}{$(0.013875476790)$} & $\mathrm{T} 1=16.793602$ & $\mathrm{~S}=0.104748$ \\
\hline
\end{tabular}

Table 23. QST $1_{1}$ Variable

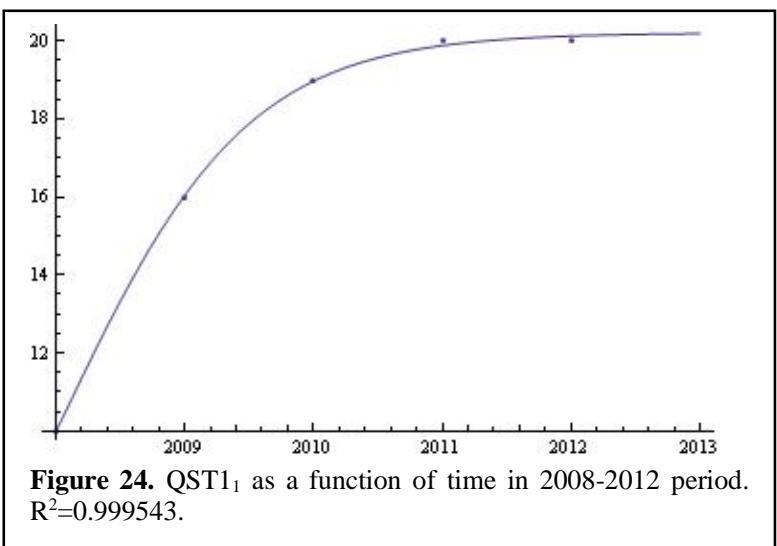


Second term,

\begin{tabular}{|l|l|l|l|l|}
\hline$\alpha$ & $\beta_{1}$ & $\gamma_{1}$ & $\delta_{1}$ & $\mu_{1}$ \\
\hline 0 & 14 & $4.76538 \mathrm{e}-12$ & 26.746 & 2010.25 \\
\hline & $\beta_{2}$ & $\gamma_{2}$ & $\delta_{2}$ & $\mu_{2}$ \\
\hline & 18 & 11.0001 & -0.894831 & 2008.25 \\
\hline C Matrix & $\begin{array}{l}\text { Mean of transformed } \\
\text { function }\end{array}$ & $\begin{array}{l}\text { Estimation } \\
\text { Error }\end{array}$ \\
\hline$\left(\begin{array}{cc}0.002037998766 & -0.001193622240 \\
-0.001193622240 & 0.003567372978\end{array}\right)$ & $\begin{array}{l}\mathrm{T} 1=9.343816 \\
\mathrm{~T} 2=7.034864\end{array}$ & $\mathrm{~S}=2.814901$ \\
\hline
\end{tabular}

Table 24. $\mathrm{QST}_{2}$ Variable

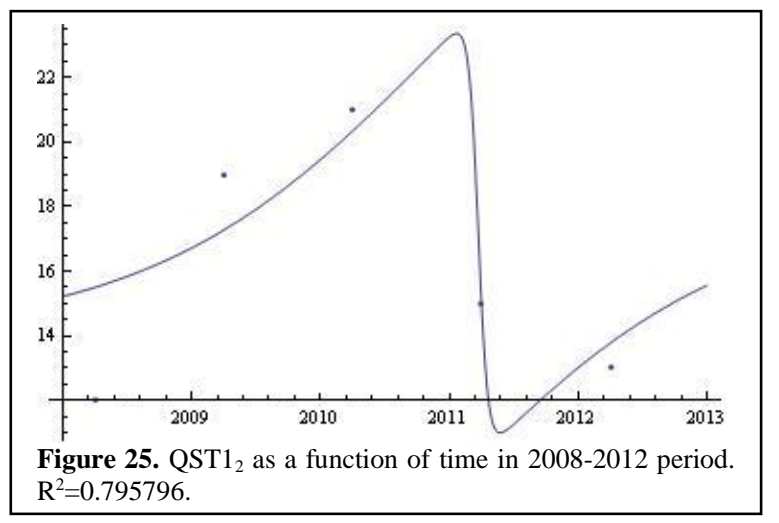

Third term,

\begin{tabular}{|l|l|l|l|l|}
\hline$\alpha$ & $\beta_{1}$ & $\gamma_{1}$ & $\delta_{1}$ & $\mu_{1}$ \\
\hline-14.9344 & 15 & 0.0757802 & 39.1546 & 2011.5 \\
\hline & $\beta_{2}$ & $\gamma_{2}$ & $\delta_{2}$ & $\mu_{2}$ \\
\hline C Matrix & 30 & 1.15316 & -2.75255 & 2008.5 \\
\hline$\left(\begin{array}{llll}0.006370849146 & 0.001910306698 \\
0.001910306698 & 0.005684729361\end{array}\right)$ & $\begin{array}{l}\text { Mean of transformed } \\
\text { function }\end{array}$ & $\begin{array}{l}\mathrm{T} 1=11.788674 \\
\mathrm{~T} 2=26.345729\end{array}$ & $\mathrm{~S}=0.043928$ \\
\hline
\end{tabular}

Table 25. QST1 $1_{3}$ Variable

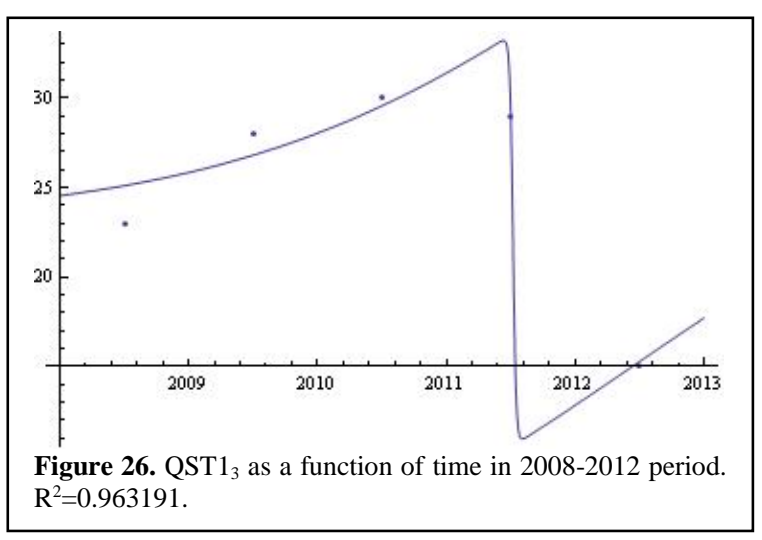


Fourth term,

\begin{tabular}{|l|l|l|l|l|}
\hline$\alpha$ & $\beta_{1}$ & $\gamma_{1}$ & $\delta_{1}$ & $\mu_{1}$ \\
\hline 0 & 14 & 0.76041 & 3.92966 & 2010.75 \\
\hline & $\beta_{2}$ & $\gamma_{2}$ & $\delta_{2}$ & $\mu_{2}$ \\
\hline C Matrix & 18 & 8.32083 & -0.727505 & 2008.75 \\
\hline$\left(\begin{array}{cc}0.002542641385 \\
-0.001112639927 & 0.003892049459\end{array}\right)$ & $\begin{array}{l}\text { Mean of transformed } \\
\text { function }\end{array}$ & $\begin{array}{l}\mathrm{T} 1=7.220449 \\
\mathrm{~T} 2=6.661526\end{array}$ & $\mathrm{~S}=0.860572$ \\
\hline
\end{tabular}

Table 26. $\mathrm{QST} 1_{4}$ Variable

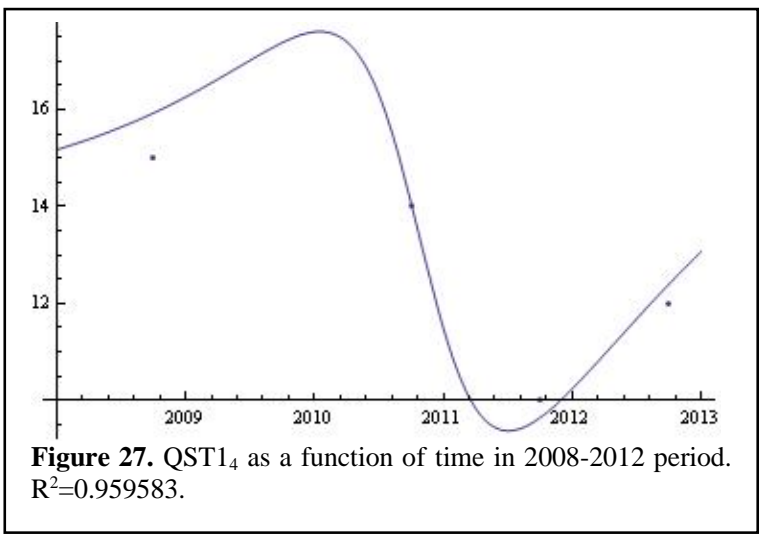


QST2 Quarterly students with quota type 2

$$
q \operatorname{st2}(t)=\left\{\begin{array}{lc}
0.888688+\frac{8}{1+0.147305 \mathrm{e}^{-0.523292(-2008+\mathrm{t})}} & \text { term } 1 \\
\frac{12}{1+0.0465639 e^{0.857155(-2008.25+\mathrm{t})}} & \text { term } 2 \\
\frac{18}{1+0.0508706 e^{0.570128(-2008.5+\mathrm{t})}} & \text { term } 3 \\
-0.411611+\frac{8}{1+2.14245 e^{-1.29718(-2008.75+\mathrm{t})}} & \text { term 4 }
\end{array}\right.
$$

First term,

\begin{tabular}{|l|l|l|l|l|}
\hline$\alpha$ & $\beta$ & $\gamma$ & $\delta$ & $\mu$ \\
\hline 0.888688 & 8 & 0.147305 & -0.523292 & 2008 \\
\hline C Matrix & Mean of transformed function & Estimation Error \\
\hline \multicolumn{2}{|c|}{$(1.979506539723)$} & $\mathrm{T} 1=7.511312$ & $\mathrm{~S}=0.949040$ \\
\hline
\end{tabular}

Table 27. QST $2_{1}$ Variable

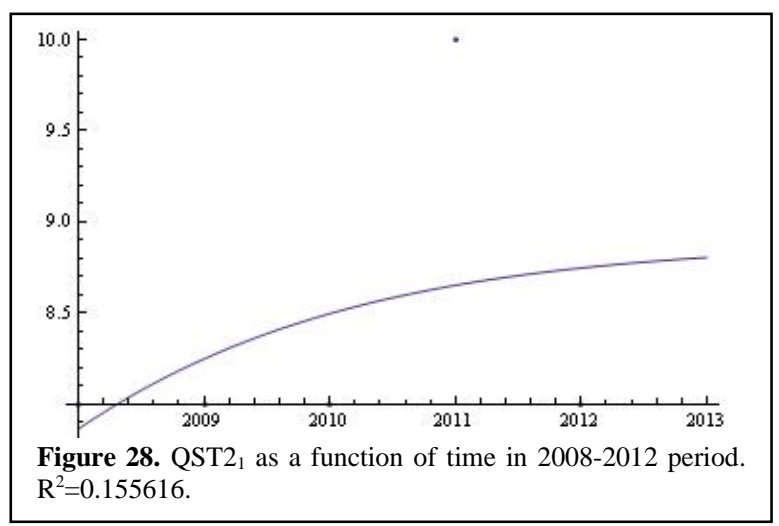

Second term,

\begin{tabular}{|l|l|l|l|l|}
\hline$\alpha$ & $\beta$ & $\gamma$ & $\delta$ & $\mu$ \\
\hline 0 & 12 & 0.0465639 & 0.857155 & 2008.25 \\
\hline C Matrix & Mean of transformed function & Estimation Error \\
\hline \multicolumn{2}{|c|}{$(0.002385568792)$} & $T 1=8.839519$ & $\mathrm{~S}=3.178865$ \\
\hline
\end{tabular}

Table 28. QST 22 Variable

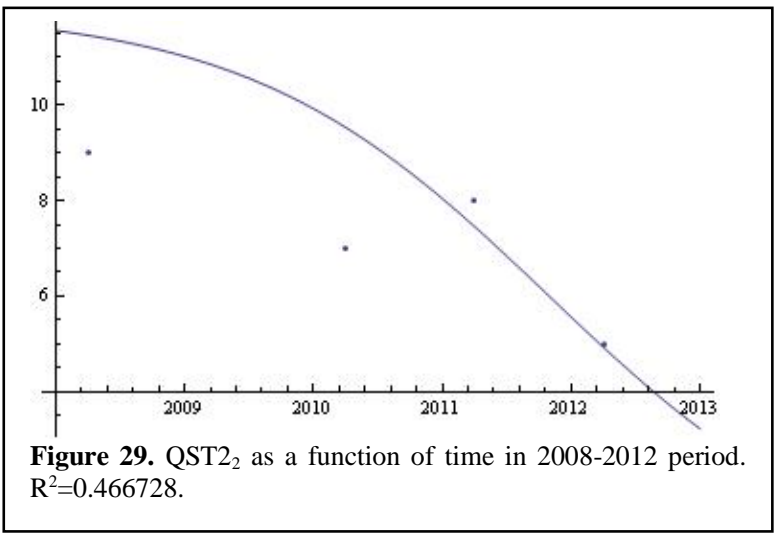


Third term,

\begin{tabular}{|l|l|l|l|l|}
\hline$\alpha$ & $\beta$ & $\gamma$ & $\delta$ & $\mu$ \\
\hline 0 & 18 & 0.0508706 & 0.570128 & 2008.5 \\
\hline C Matrix & Mean of transformed function & Estimation Error \\
\hline \multicolumn{2}{|c|}{$(0.000870273267)$} & $T 1=15.047784$ & $S=2.777999$ \\
\hline
\end{tabular}

Table 29. $\mathrm{QST} 2_{3}$ Variable

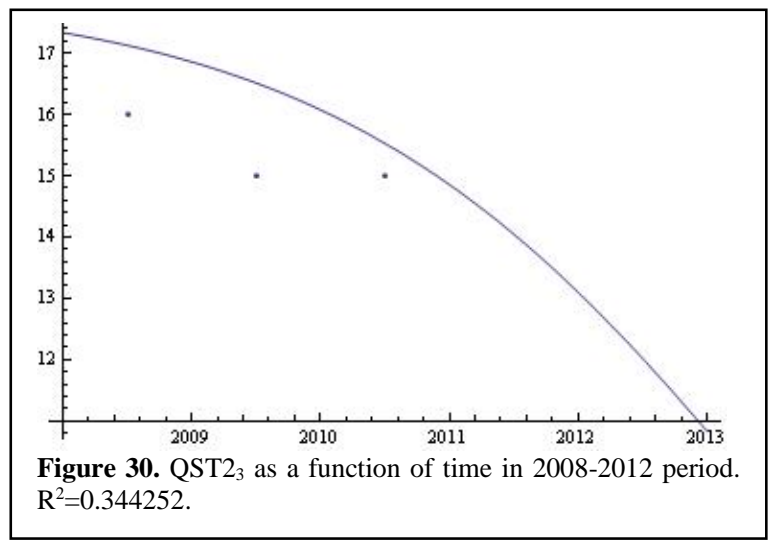

Fourth term,

\begin{tabular}{|l|l|l|l|l|}
\hline$\alpha$ & $\beta$ & $\gamma$ & $\delta$ & $\mu$ \\
\hline-0.411611 & 8 & 2.14245 & -1.29718 & 2008.75 \\
\hline C Matrix & Mean of transformed function & Estimation Error \\
\hline \multicolumn{2}{|r|}{$(0.049880951786)$} & T1=6.011611 & $S=1.669814$ \\
\hline
\end{tabular}

Table 30. QST2 ${ }_{4}$ Variable

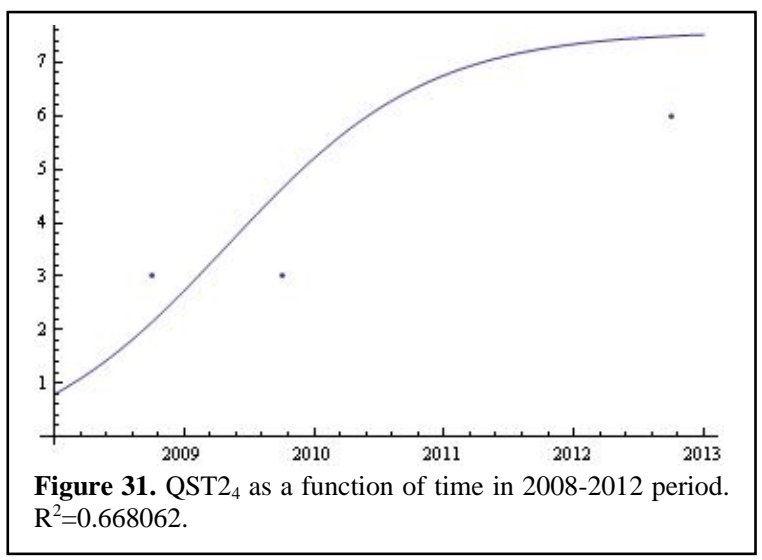




\section{QST3 Quarterly students with quota type 3}

$$
q \operatorname{st} 3(t)= \begin{cases}0.0124966+\frac{8}{1+2.12352 e^{-0.320652(-2008+\mathrm{t})}} & \text { term } 1 \\ \frac{5}{1+1.59815 e^{-0.608262(-2008.25+\mathrm{t})}} & \text { term } 2 \\ \frac{6}{1+1.47586 e^{-0.494151(-2008.5+\mathrm{t})}} & \text { term } 3 \\ -0.393176+\frac{5}{1+1.25485 e^{-1.64502(-2008.75+\mathrm{t})}} & \text { term 4 }\end{cases}
$$

First term,

\begin{tabular}{|l|l|l|l|l|}
\hline$\alpha$ & $\beta$ & $\gamma$ & $\delta$ & $\mu$ \\
\hline 0.0124966 & 8 & 2.12352 & -0.320652 & 2008 \\
\hline C Matrix & \multicolumn{2}{|l|}{ Mean of transformed function } & Estimation Error \\
\hline \multicolumn{2}{|c|}{$(0.258803130282)$} & $\mathrm{T} 1=3.787503$ & $\mathrm{~S}=1.924859$ \\
\hline
\end{tabular}

Table 31. QST3 $3_{1}$ Variable

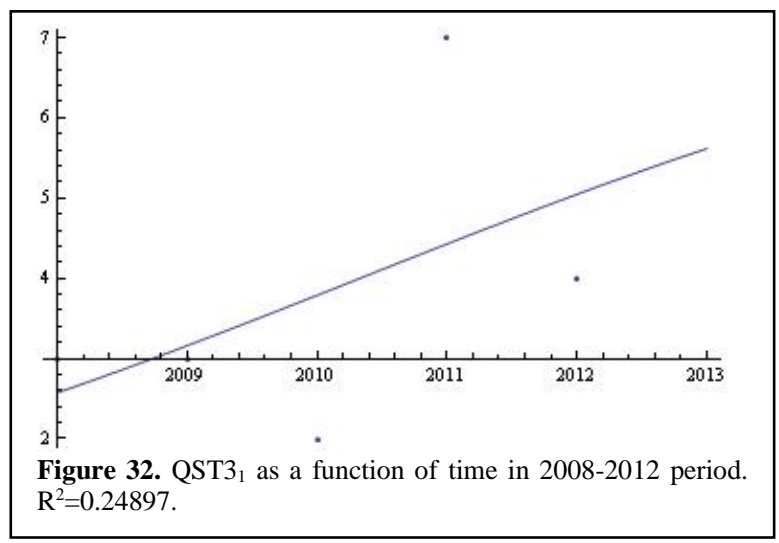

Second term,

\begin{tabular}{|l|l|l|l|l|}
\hline$\alpha$ & $\beta$ & $\gamma$ & $\delta$ & $\mu$ \\
\hline 0 & 5 & 1.59815 & -0.608262 & 2008.25 \\
\hline C Matrix & Mean of transformed function & Estimation Error \\
\hline \multicolumn{2}{|c|}{$(0.017421348874)$} & $T 1=3.270446$ & $\mathrm{~S}=1.118203$ \\
\hline
\end{tabular}

Table 32. $\mathrm{QST}_{2}$ Variable

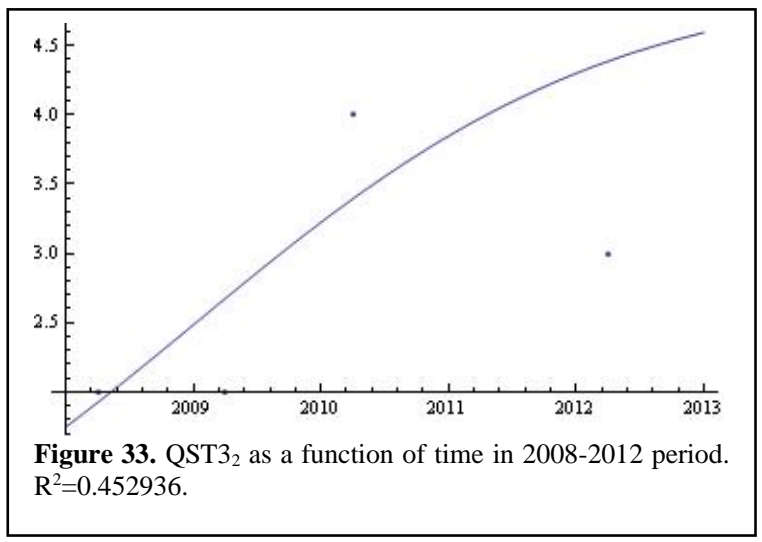


Third term,

\begin{tabular}{|l|l|l|l|l|}
\hline$\alpha$ & $\beta$ & $\gamma$ & $\delta$ & $\mu$ \\
\hline 0 & 6 & 1.47586 & -0.494151 & 2008.5 \\
\hline C Matrix & Mean of transformed function & Estimation Error \\
\hline \multicolumn{2}{|c|}{$(0.013184120579)$} & $\mathrm{T} 1=3.785736$ & $\mathrm{~S}=1.179239$ \\
\hline
\end{tabular}

Table 33. $\mathrm{QST}_{3}$ Variable

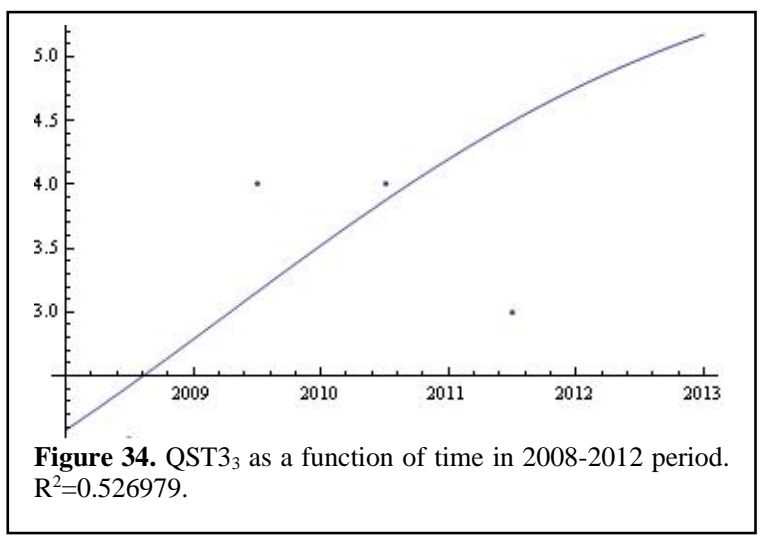

Fourth term,

\begin{tabular}{|l|l|l|l|l|}
\hline$\alpha$ & $\beta$ & $\gamma$ & $\delta$ & $\mu$ \\
\hline-0.393176 & 5 & 1.25485 & -1.64502 & 2008.75 \\
\hline C Matrix & Mean of transformed function & Estimation Error \\
\hline \multicolumn{2}{|c|}{$(0.182146384354)$} & $T 1=4.193176$ & $S=1.371107$ \\
\hline
\end{tabular}

Table 34. QST3 ${ }_{4}$ Variable

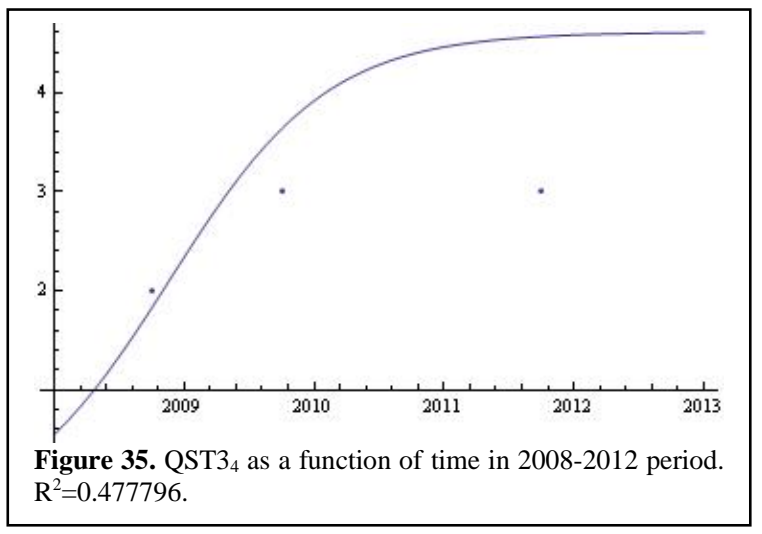




\section{QST4 Quarterly students with quota type 4}

$$
\operatorname{qst} 4(t)=\left\{\begin{array}{cc}
\frac{2.9}{1+1.2773 \cdot 10^{6} \mathrm{e}^{-5.73568(-2008+\mathrm{t})}} & \text { term } 1 \\
1.68485+\frac{5}{1+458.881 e^{-1.51957(-2008.25+\mathrm{t})}} & \text { term } 2 \\
9.41936+\frac{12}{1+15.8177 e^{-0.384379(-2008.5+\mathrm{t})}} & \text { term } 3 \\
7.56 \cdot 10^{-7}+\frac{5}{1+1.73789 \cdot 10^{-10} e e^{14.9835(-2008.75+\mathrm{t})}} & \text { term } 4
\end{array}\right.
$$

First term,

\begin{tabular}{|l|l|l|l|l|}
\hline$\alpha$ & $\beta$ & $\gamma$ & $\delta$ & $\mu$ \\
\hline 0 & 2.9 & $1.2773 \mathrm{e} 6$ & -5.73568 & 2008 \\
\hline C Matrix & Mean of transformed function & Estimation Error \\
\hline \multicolumn{2}{|c|}{$(0.061805865790)$} & $\mathrm{T} 1=1.176670$ & $\mathrm{~S}=0.592191$ \\
\hline
\end{tabular}

Table 35. QST4 1 Variable

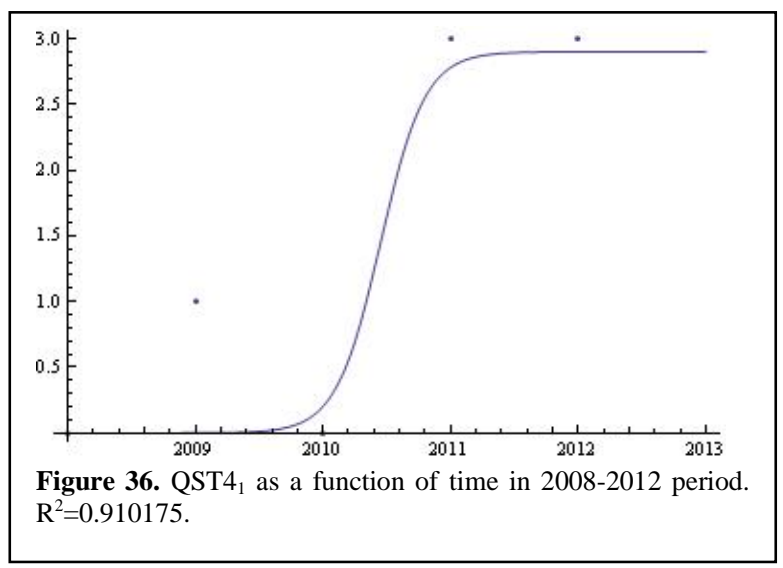

Second term,

\begin{tabular}{|l|l|l|l|l|}
\hline$\alpha$ & $\beta$ & $\gamma$ & $\delta$ & $\mu$ \\
\hline 1.68485 & 5 & 458.881 & -1.51957 & 2008.25 \\
\hline C Matrix & Mean of transformed function & Estimation Error \\
\hline \multicolumn{2}{|c|}{$(0.239669233569)$} & $\mathrm{T} 1=0.715149$ & $\mathrm{~S}=0.631693$ \\
\hline
\end{tabular}

Table 36. $\mathrm{QST}_{2}$ Variable

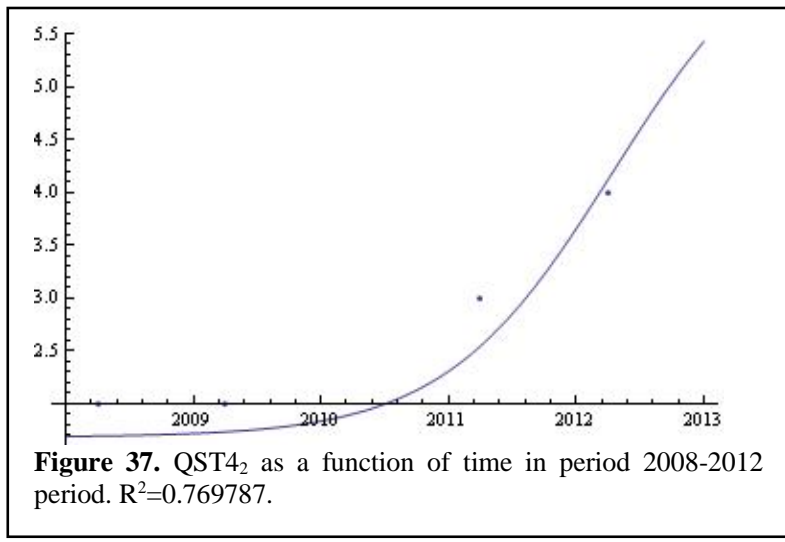


Third term,

\begin{tabular}{|l|l|l|l|l|}
\hline$\alpha$ & $\beta$ & $\gamma$ & $\delta$ & $\mu$ \\
\hline-0.628319 & 12 & 1.12909 & -3.30855 & 2008.5 \\
\hline C Matrix & Mean of transformed function & Estimation Error \\
\hline \multicolumn{2}{|c|}{$(0.031931458961)$} & $\mathrm{T} 1=10.628319$ & $\mathrm{~S}=0.936932$ \\
\hline
\end{tabular}

Table 37. QST4 $4_{3}$ Variable

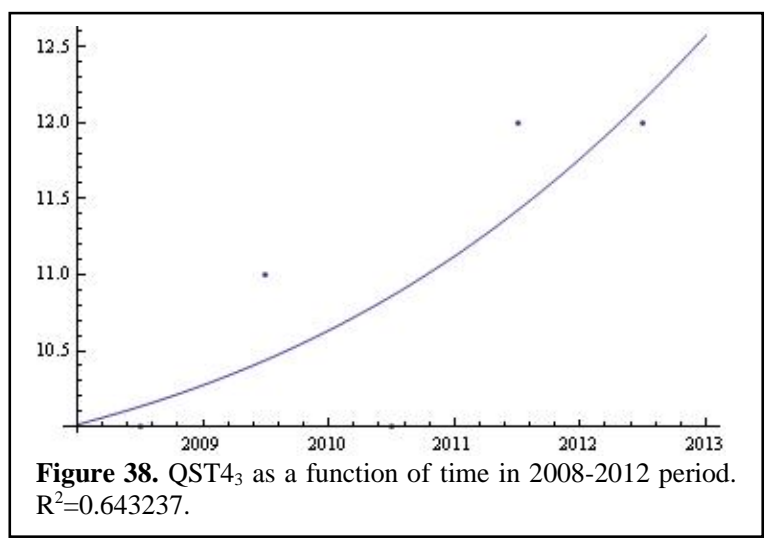

Fourth term,

\begin{tabular}{|l|l|l|l|l|}
\hline$\alpha$ & $\beta$ & $\gamma$ & $\delta$ & $\mu$ \\
\hline $7.56994 \mathrm{e}-7$ & 2 & $1.73789 \mathrm{e}-10$ & 14.9835 & 2008.75 \\
\hline C Matrix & Mean of transformed function & Estimation Error \\
\hline \multicolumn{2}{|c|}{$(0.208527010191)$} & $\mathrm{T} 1=0.799999$ & $\mathrm{~S}=0.000695$ \\
\hline
\end{tabular}

Table 38. $\mathrm{QST}_{4}$ Variable

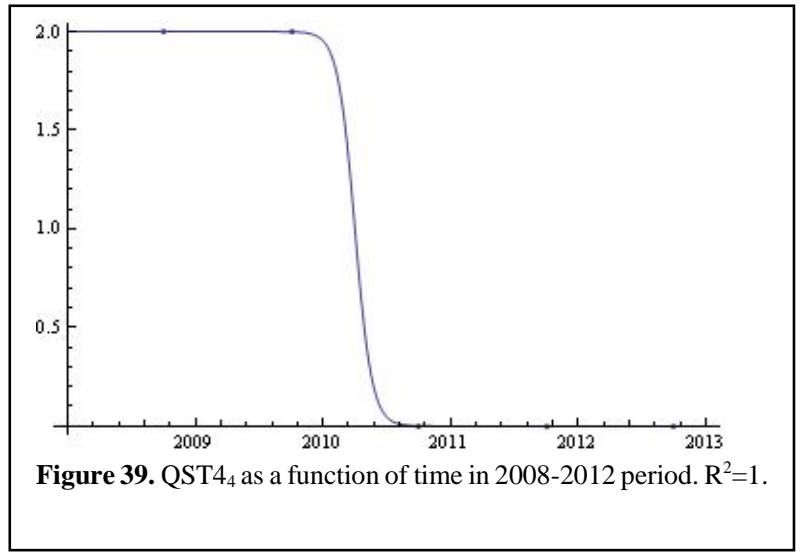


TAX1 Percentage Tax type 1 for water

$$
\operatorname{tax} 1(t)=0.0699988+\frac{0.0100024}{1+1.53253 \cdot 10^{61} e^{-53.6883(-2008+t)}}
$$

\begin{tabular}{|l|l|l|l|l|}
\hline$\alpha$ & $\beta$ & $\gamma$ & $\delta$ & $\mu$ \\
\hline 0.0699988 & 0.0100024 & $1.53253 \mathrm{e} 61$ & -53.6883 & 2008 \\
\hline C Matrix & Mean of transformed function & Estimation Error \\
\hline \multicolumn{2}{|c|}{$(2020.204795076782)$} & $\mathrm{T} 1=0.004501$ & $\mathrm{~S}=0.000004$ \\
\hline
\end{tabular}

Table 40. TAX1 Variable

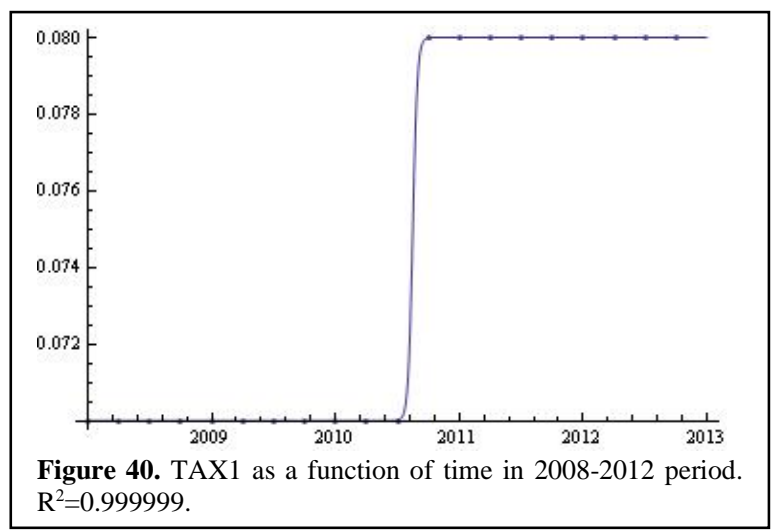

TAX2 Percentage Tax type 2 for general values

$$
\operatorname{tax} 2(t)=0.158421+\frac{0.1}{1+159.501 e^{-1.05128(-2008+t)}}
$$

\begin{tabular}{|l|l|l|l|l|}
\hline$\alpha$ & $\beta$ & $\gamma$ & $\delta$ & $\mu$ \\
\hline 0.158421 & 0.1 & 159.501 & -1.05128 & 2008 \\
\hline C Matrix & Mean of transformed function & Estimation Error \\
\hline \multicolumn{2}{|r|}{$(240.993857427178)$} & $\mathrm{T} 1=0.013579$ & $\mathrm{~S}=0.006230$ \\
\hline
\end{tabular}

Table 40. TAX2 Variable

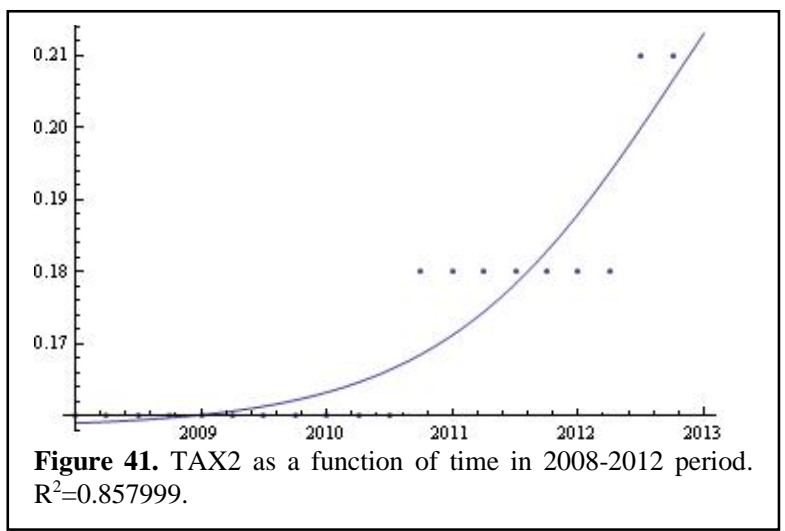


TAX3 Percentage Tax type 3 to apply to profits of an enterprise

$$
\operatorname{tax} 3(t)=0.12
$$

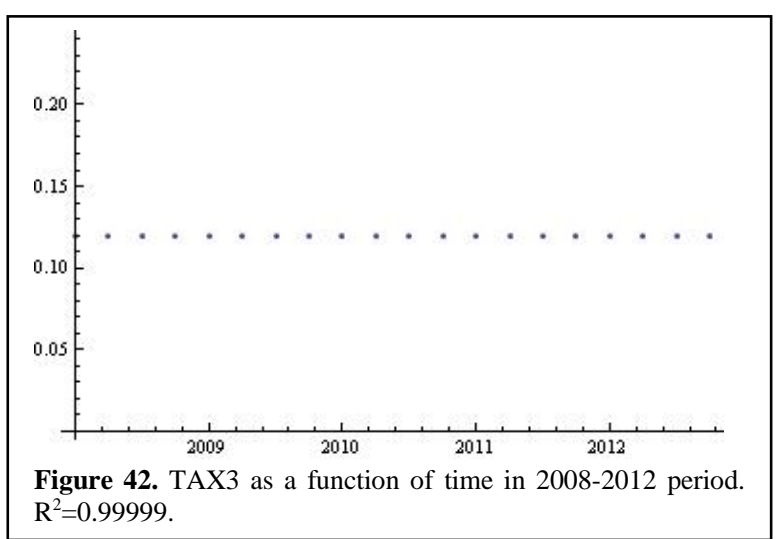




\section{Appendix IV}

Sensitivity Analysis

\begin{tabular}{|c|c|c|c|c|}
\hline $\begin{array}{c}\text { Indepe } \\
\text { ndent } \\
\text { variable } \\
x\end{array}$ & $\begin{array}{l}\text { Equations } \\
y=m x+n \\
y=a x^{2}+b x+c\end{array}$ & $\mathbf{R}^{2}$ & Derivative Function & $\begin{array}{l}\text { Confidence interval } \\
\text { for " } m \text { " or " } 2 a \text { " }\end{array}$ \\
\hline TQSW & $5455.04-275.904 x+4.5656 x^{2}$ & 0.22 & $-275.904+9.13119 x$ & $(-0.671313,18.9337)$ \\
\hline QFCO & -- & -- & -- & -- \\
\hline$A C T E$ & -- & -- & -- & -- \\
\hline$O Q E X$ & $463.942+9.40251 \mathrm{x}-0.0088123 \mathrm{x}^{2}$ & 0.48 & $9.40251-0.0176248 \mathrm{x}$ & $(-0.0284,-0.00686)$ \\
\hline AINP & -- & -- & -- & -- \\
\hline$S S C C$ & -- & -- & -- & -- \\
\hline BSAW & -- & -- & -- & -- \\
\hline TQSL & $7570.35-110.582 x+0.453796 x^{2}$ & 0.32 & $-110.582+0.907591 x$ & $(0.192097,1.62308)$ \\
\hline QST1 & $-1307.78+201.596 x$ & 0.74 & 201.596 & $(141.758,261.434)$ \\
\hline QST2 & $1029.73+126.641 x$ & 0.15 & 126.641 & $(-22.5973,275.879)$ \\
\hline QST3 & -- & -- & -- & -- \\
\hline QST4 & $1725.84+135.429 \mathrm{x}$ & 0.16 & 135.429 & $(-16.2402,287.097)$ \\
\hline TAXI & -- & -- & -- & -- \\
\hline$T A X 2$ & -- & -- & -- & -- \\
\hline \multicolumn{5}{|c|}{$\begin{array}{l}\text { Table 41: Equations for the best fit of the profit after taxes " } y \text { " with the input variables. The actual data of a } \\
\text { small business are used in the 2008-2012 period, by quarters. Dashes indicate that no direct link has been } \\
\text { found between the considered variables. }\end{array}$} \\
\hline
\end{tabular}

\begin{tabular}{|c|c|c|c|c|c|}
\hline $\begin{array}{c}\text { Indepen } \\
\text { dent } \\
\text { variable } \\
x\end{array}$ & $\begin{array}{l}\text { Equations } \\
y=m x+n ; \\
y=a x^{2}+b x+c\end{array}$ & $\mathbf{R}^{2}$ & $\begin{array}{l}\text { Derivative } \\
\text { Function }\end{array}$ & $\begin{array}{l}\text { Confidence interval } \\
\text { for " } m \text { " or " } 2 a \text { " }\end{array}$ & \\
\hline$T Q S W$ & $1727.29+20.3186 x$ & 0.94 & 20.3186 & $(16.766,23.8713)$ & \\
\hline$Q F C O$ & -- & -- & -- & -- & \\
\hline$A C T E$ & -- & -- & -- & -- & \\
\hline OQEX & $1724.09+2.41122 \mathrm{x}$ & 0.87 & 2.41122 & $(1.99077,2.83167)$ & \\
\hline AINP & -- & -- & -- & -- & \\
\hline$S S C C$ & -- & -- & -- & -- & \\
\hline$B S A W$ & -- & -- & -- & -- & \\
\hline TQSL & $1705.36+20.4975 x$ & 0.88 & 20.4975 & $(17.0786,23.9164)$ & \\
\hline QST1 & $33.098+121.811 \mathrm{x}$ & 0.24 & 121.811 & $(26.0076,217.615)$ & \\
\hline QST2 & -- & -- & -- & -- & \\
\hline QST3 & -- & -- & -- & -- & \\
\hline QST4 & $2557.35-157.792 x$ & 0.75 & -157.792 & $(-198.169,-117.414)$ & \\
\hline TAXI & -- & -- & -- & -- & \\
\hline TAX2 & -- & -- & -- & -- & \\
\hline \multicolumn{6}{|c|}{$\begin{array}{l}\text { Table 42: Equations for the best fit of the profit after taxes " } y \text { " with the input variables. The actual data of } \\
\text { a small business are used in the } 2013-2025 \text { period, by quarters. Dashes indicate that no direct link has been } \\
\text { found between the considered variables. }\end{array}$} \\
\hline
\end{tabular}

